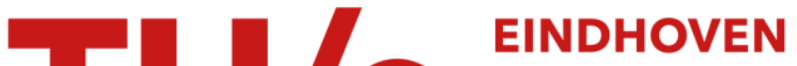 UNIVERSITY OF TECHNOLOGY
}

\section{Structure and function of the catalyst and the promoter in Co- Mo hydrodesulfurization catalysts}

\section{Citation for published version (APA):}

Prins, R., Beer, de, V. H. J., \& Somorjai, G. A. (1989). Structure and function of the catalyst and the promoter in Co-Mo hydrodesulfurization catalysts. Catalysis Reviews : Science and Engineering, 31(1-2), 1-41. https://doi.org/10.1080/01614948909351347

DOI:

10.1080/01614948909351347

Document status and date:

Published: 01/01/1989

\section{Document Version:}

Publisher's PDF, also known as Version of Record (includes final page, issue and volume numbers)

\section{Please check the document version of this publication:}

- A submitted manuscript is the version of the article upon submission and before peer-review. There can be important differences between the submitted version and the official published version of record. People interested in the research are advised to contact the author for the final version of the publication, or visit the $\mathrm{DOI}$ to the publisher's website.

- The final author version and the galley proof are versions of the publication after peer review.

- The final published version features the final layout of the paper including the volume, issue and page numbers.

Link to publication

\section{General rights}

Copyright and moral rights for the publications made accessible in the public portal are retained by the authors and/or other copyright owners and it is a condition of accessing publications that users recognise and abide by the legal requirements associated with these rights.

- Users may download and print one copy of any publication from the public portal for the purpose of private study or research.

- You may not further distribute the material or use it for any profit-making activity or commercial gain

- You may freely distribute the URL identifying the publication in the public portal.

If the publication is distributed under the terms of Article 25fa of the Dutch Copyright Act, indicated by the "Taverne" license above, please follow below link for the End User Agreement:

www.tue.nl/taverne

Take down policy

If you believe that this document breaches copyright please contact us at:

openaccess@tue.nl

providing details and we will investigate your claim. 
CATAL. REV.-SCI. ENG., 31(1\&2), 1-41 (1989)

\section{Structure and Function of the Catalyst and the Promoter in $\mathrm{Co}-\mathrm{Mo}_{\mathrm{O}}$ Hydrodesulfurization Catalysts}

\section{R. PRINS* AND V. H. J. DE BEER}

Laboratory for Inorganic Chemistry

Eindhoven University of Technology

P.O. Box 513, 5600 MB Eindhoven, The Netherlands

\section{G. A. SOMORJAI}

Materials and Molecular Research Division

Lawrence Berkeley Laboratory, and

Department of Chemistry

University of California

Berkeley, California; U.S.A.

I. INTRODUCTION .................... 2

II. STRUCTURE AND COMPOSITION OF THE

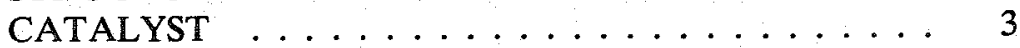

A. The $\mathrm{Mo}-\mathrm{S} / \gamma-\mathrm{Al}_{2} \mathrm{O}_{3} \mathrm{System} \ldots \ldots \ldots \ldots$

B. The $\mathrm{Co}-\mathrm{Mo}-\mathrm{S} / \gamma-\mathrm{Al}_{2} \mathrm{O}_{3}$ System . ........ 5

${ }^{*}$ To whom correspondence should be addressed at his present address: TechnischChemisches Laboratorium, 8092 Zürich, Switzerland. 
III. MODELS OF THE HDS REACTION MECHANISMS OVER THE Mo-S $/ \gamma-\mathrm{Al}_{2} \mathrm{O}_{3}$ SYSTEM AND EXPERIMENTAL VERIFICATIONS ........ 8

A. Solid-State Model . . . . . . . . . . . . . . . 8

B. Organometallic Chemistry Models ......... 11

C. Surface Science Model . . . . . . . . . . . . . 19

IV. ROLE OF THE COBALT PROMOTER . . . . . . 25

A. Co as a Textural Promoter . . . . . . . . . 25

B. Co Role in Hydrogen Spillover . . . . . . . . 27

C. Co Role as Bonding Modifier of the Mo Site . . . . . 28

D. Determination of the Number of Active Sites . . . . 30

E. Co as Producer of a New Catalytic Site ....... 32

V. CONCLUSIONS AND DIRECTIONS FOR THE

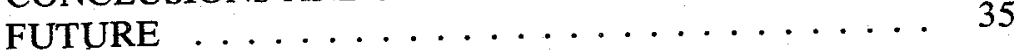

REFERENCES

\section{INTRODUCTION}

The removal of sulfur, nitrogen, oxygen, and metals from oil by reductive treatments in so-called hydrotreating processes has been of paramount importance ever since oil began to be used as an energy source. Oil and oil products have to be purified because most catalysts which are used for further processing of oil products cannot tolerate sulfur and metals. A further reason for cleanup is to diminish air-polluting emissions of sulfur and nitrogen oxides which contribute to acid rain. Although the origin of hydrotreating catalysts goes back to the 1920 s when German researchers developed catalysts to liquefy coal, it was not before the 70s that a fair understanding of the structure of these catalysts and of the mechanism of their catalytic action was developed. Thus, in the '70s it was established that under actual catalytic conditions the majority of the molybdenum (or tungsten) in industrial hydrotreating catalysts is present in the form of small $\mathrm{MoS}_{2}\left(\mathrm{WS}_{2}\right)$ particles in the pores of the $\gamma-\mathrm{Al}_{2} \mathrm{O}_{3}$ support. Although there was already much discussion on the role and structure of cobalt and nickel, which are commonly used in the industry as promoters for the catalytic activity, it was only in the ' 80 s that a full understanding of the location of the promoter ions in the hydrotreating catalysts was developed. In the past years new suggestions for the mechanisms of hydrodesulfurization (HDS), hydrodenitrogenation (HDN), hydrodeoxygenation (HDO), and hydrodemetallization 
(HDM) have also been put forward. In this paper we are only concerned with the mechanism of the HDS reaction, since it is about this reaction that most knowledge has been accumulated. For other hydrotreating work we refer to recent articles on $\operatorname{HDN}[1,2]$, HDO $[3,4]$ and HDM [5], and to the references cited therein.

Since sulfide catalysts are used in all hydrotreating processes, the information provided in this review on catalyst structure is relevant not only for HDS, but also for all other hydrotreating processes. One has to take into account that while cobalt is mainly used as a promoter for sulfided $\mathrm{Mo} / \mathrm{Al}_{2} \mathrm{O}_{3}$ in $\mathrm{HDS}$, nickel is usually favored in HDN. Sometimes tungsten is used instead of molybdenum. In this review we mainly discuss the properties of $\mathrm{Al}_{2} \mathrm{O}_{3}$-supported $\mathrm{Mo}$ and $\mathrm{Co}-\mathrm{Mo}$, but because of the similarity in chemical properties, most of the information on $\mathrm{Co}$ also applies for $\mathrm{Ni}$, and most of the information on Mo applies also for $\mathrm{W}$.

The wealth of information which has become available in recent years from Mössbauer, EXAFS, TEM, and other studies has provided a clear picture of the structure of HDS catalysts and especially of the location of the promoter. These studies and new developments in surface science and organometallic chemistry make a review of these accomplishments necessary. Work carried out before 1980 is only briefly described in this review. For reviews of work carried out before 1980 we refer the reader to the review articles by De Beer and Schuit [6], Massoth [7], Grange [8], and Ratnasamy and Sivasanker [9]. For preparational aspects of hydrotreating catalysts we likewise refer the reader to these articles.

In Section II we first discuss the structure of a HDS catalyst and especially the location and structure of the molybdenum and cobalt ions at the catalyst surface. Before embarking on a full discussion of the role of the cobalt promoter in Section IV, Section III reveals the current state of thinking about the function of the molybdenum site in an unpromoted catalyst. We finish with our conclusions about what has been definitely proven about the structure and function of catalyst and promoter in HDS catalysts and what is still open to discussion and should be actively pursued in further research.

\section{STRUCTURE AND COMPOSITION OF THE CATALYST}

\section{A. The $\mathrm{Mo}-\mathrm{S} / \gamma-\mathrm{Al}_{2} \mathrm{O}_{3}$ System}

HDS catalysts are normally made by pore volume impregnation of $\gamma-\mathrm{Al}_{2} \mathrm{O}_{3}$ with aqueous solutions of $\left(\mathrm{NH}_{4}\right)_{6} \mathrm{Mo}_{7} \mathrm{O}_{24}$ and $\mathrm{Co}\left(\mathrm{NO}_{3}\right)_{2}$, with intermediate drying and calcination steps. The resulting oxidic pre- 
cursor of the catalyst is transformed into the actual HDS catalyst by a sulfiding procedure which may consist of treating in a mixture of $\mathrm{H}_{2} \mathrm{~S}$ and $\mathrm{H}_{2}$ or thiophene and $\mathrm{H}_{2}$, or in a liquid feed of sulfur-containing molecules and $\mathrm{H}_{2}$. Today, most workers agree that the resulting catalyst is (almost) completely sulfided; that is, the $\mathrm{MoO}_{3}$ is transformed into $\mathrm{MoS}_{2}$ and the cobalt ions have passed from an oxidic into a sulfidic environment. During sulfiding, as well as during actual HDS, the conditions are highly reducing with $\mathrm{H}_{2} \mathrm{~S}$ always present, and thermodynamics predict that molybdenum should be in the $\mathrm{MoS}_{2}$ form, cobalt in the $\mathrm{CO}_{9} \mathrm{~S}_{8}$, and nickel in the $\mathrm{Ni}_{3} \mathrm{~S}_{2}$ form. Indeed, EXAFS studies of the Mo K-edge absorption spectra demonstrated that in sulfided $\mathrm{Mo} / \mathrm{Al}_{2} \mathrm{O}_{3}$ catalysts the average $\mathrm{Mo}$ ion has the same environment as a Mo ion in $\mathrm{MoS}_{2}[10-12]$. The only difference was that in the catalyst the $\mathrm{N}(\mathrm{Mo}-\mathrm{Mo})$ coordination number for the second shell of (molybdenum) neighbors surrounding each Mo ion was less than 6 , the value found in pure $\operatorname{MoS}_{2}$. This indicates either that the $\mathrm{MoS}_{2}$ particles on the $\mathrm{Al}_{2} \mathrm{O}_{3}$ surface are small, or that the longrange order in these particles is not perfect. Also, temperature-programmed sulfidation studies have shown that the kinetics of sulfidation are fast enough to transform the majority of $\mathrm{Mo}$ and Co into the sulfidic form [13, 14].

$\mathrm{MoS}_{2}$ has a layer lattice and the sulfur-sulfur interaction between sandwich domains of $\mathrm{MoS}_{2}$ layers is weak. Crystals grow in the form of platelets, with large dimensions parallel to the basal sulfur planes and a small dimension perpendicular to the basal plane. Topsøe et al. claim that $\mathrm{MoS}_{2}$ can be present on industrial supports as very large patches of a wrinkled, one-slab-thick $\mathrm{MoS}_{2}$ layer [15]. In other studies threedimensional-like structures were described. In a recent HRTEM model study of HDS catalysts, $\mathrm{MoS}_{2}$ crystallites were created on planar $\mathrm{Al}_{2} \mathrm{O}_{3}$ [16]. On this support the $\mathrm{MoS}_{2}$ crystallites occurred in the form of platelets with a height-to-width ratio between 0.4 and 0.7 . Some of these platelets were oriented with their basal plane parallel to the $\mathrm{Al}_{2} \mathrm{O}_{3}$ surface and some were oriented at a nonzero angle to the surface, suggesting that the $\mathrm{MoS}_{2}$ platelets are bonded to the $\mathrm{Al}_{2} \mathrm{O}_{3}$ surface by $\mathrm{Mo}-\mathrm{O}-\mathrm{Al}$ bonds (Fig. 1).

Models of the active sites in $\mathrm{Mo}-\mathrm{S} / \gamma-\mathrm{Al}_{2} \mathrm{O}_{3}$ catalysts have usually been developed by consideration of the morfology of $\mathrm{MoS}_{2}$. On the basis of bond energy considerations, Voorhoeve had already assumed in 1971 that the anions in the basal planes of $\mathrm{MoS}_{2}$ are more strongly bonded to the Mo cations than the anions at edges or corners (as in the layer lattice of $\mathrm{TiCl}_{3}$ ). Therefore catalysis most likely occurs at edges and corners, and not at basal planes [17]. Experimental 


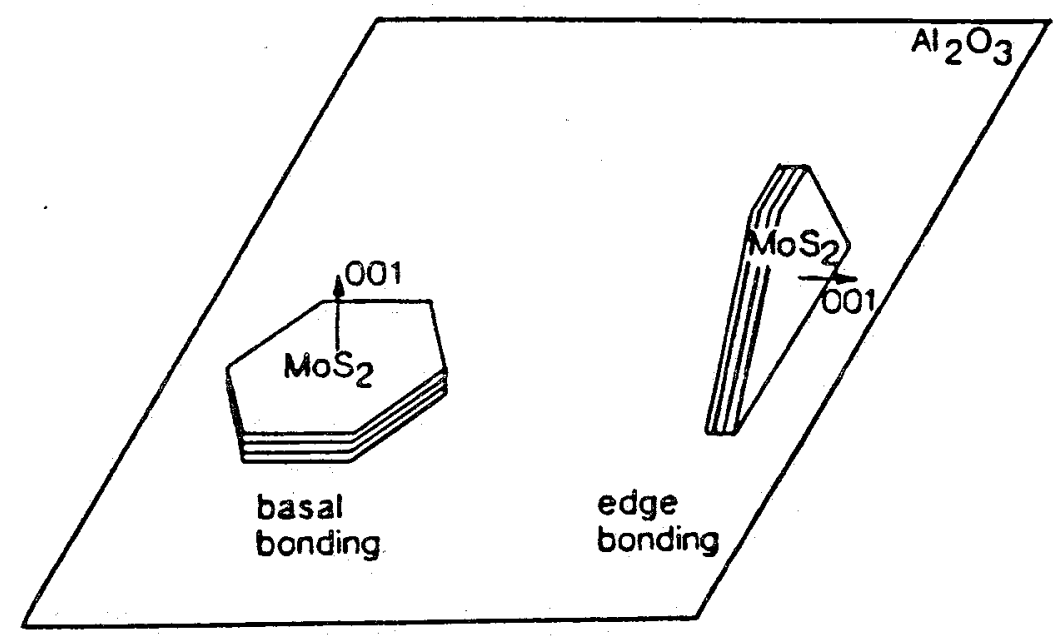

FIG. 1. Orientation of small $\mathrm{MoS}_{2}$ crystallites on the surface of $\mathrm{Al}_{2} \mathrm{O}_{3}$.

verification for this has been provided by a surface science study of the catalytic activity of a $\mathrm{MoS}_{2}$ single crystal. Salmeron et al. showed that such a crystal, with a large ratio of basal plane over edge surface area, has a negligible activity for the HDS of thiophene [18]. However, sputtering of the basal plane and exposure of Mo ions increased the activity [19].

\section{B. The $\mathrm{Co}-\mathrm{Mo}-\mathrm{S} / \gamma-\mathrm{Al}_{2} \mathrm{O}_{3}$ System}

Many spectroscopic techniques are capable of detecting the presence of cobalt in one structure or another, but until the application of Mössbauer spectroscopy no technique could quantitatively determine the simultaneous presence of different cobalt structures. Primarily due to the inverse Mössbauer studies by the Topsøe group, a quantitative picture has emerged in recent years about the structure of cobalt in HDS catalysts [20-22].

Cobalt can exist in several forms in a promoted $\mathrm{Mo} / \mathrm{Al}_{2} \mathrm{O}_{3}$ catalyst. In the oxidic precursor form, cobalt ions interact strongly with the spinel type $\gamma-\mathrm{Al}_{2} \mathrm{O}_{3}$ lattice and occupy octahedral sites just below the $\mathrm{Al}_{2} \mathrm{O}_{3}$ surface or tetrahedral sites in the $\mathrm{Al}_{2} \mathrm{O}_{3}$ bulk $[8,22-24]$. At higher loadings cobalt can also form $\mathrm{Co}_{3} \mathrm{O}_{4}$ crystallites on the surface of the support. In the sulfidic form, cobalt may be present in three 
forms, as $\mathrm{Co}_{9} \mathrm{~S}_{8}$ crystallites on the support, as cobalt ions adsorbed onto the surface of $\mathrm{MoS}_{2}$ crystallites (vide infra), and in tetrahedral sites in the $\gamma-\mathrm{Al}_{2} \mathrm{O}_{3}$ lattice [20]. Depending on the relative concentrations of cobalt and molybdenum [21] and on the pretreatment [25], a sulfided catalyst contains a relatively large amount either of $\mathrm{Co}_{9} \mathrm{~S}_{8}$ or of cobalt adsorbed on $\mathrm{MoS}_{2}$ [23] (Topsøe et al. called this structure the $\mathrm{Co}-\mathrm{Mo}-\mathrm{S}$ phase). The structure of the catalyst in the sulfided fore $\mathrm{Co}_{3} \mathrm{O}_{4}$ was found to transform into $\mathrm{Co}_{9} \mathrm{~S}_{8}$, cobalt ions in octahedral support sites transformed into cobalt adsorbed on $\mathrm{MoS}_{2}$ ( $\mathrm{Co}-\mathrm{Mo}-\mathrm{S}$ phase), and cobalt ions in tetrahedral support sites remained in those positions [20].

By combining the Mössbauer studies with catalytic activity studies, Topsøe et al. established that the promoter effect of cobalt is related to the cobalt ions adsorbed on $\mathrm{MoS}_{2}$ [21]. They have therefore confirmed suggestions made by Voorhoeve and Stuiver [17] and by Farragher and Cossee [26] that the promoter effect is not due to separate $\mathrm{Co}_{9} \mathrm{~S}_{8}$ crystallites but to cobalt ions in contact with $\mathrm{MoS}_{2}$. Originally the occurrence of this adsorption state was somewhat confusing, since thermodynamically the most stable phase of cobalt under sulfidic conditions is $\mathrm{Co}_{9} \mathrm{~S}_{8}$. Furthermore, solid-state chemistry studies have shown that $\mathrm{CoMo}_{2} \mathrm{~S}_{4}$ is catalytically inactive [27-29] and that cobalt does not form ternary compounds with $\mathrm{MoS}_{2}$, as it does with $\mathrm{NbS}_{2}$ and $\mathrm{TaS}_{2}[30,31]$. Nevertheless it can adsorb on the surface of $\mathrm{MoS}_{2}$ crystallites. Farragher was the first to suggest that the cobalt is located at the edges of the $\mathrm{MoS}_{2}$ platelets $[26,32]$. Proof for this suggestion was obtained by Chianelli et al. in scanning Auger studies of cobalt-promoted single crystals of $\mathrm{MoS}_{2}$ [33]. An EXAFS study of the Co K-edge demonstrated that the cobalt ions in a sulfided $\mathrm{Co}-\mathrm{Mo} / \mathrm{Al}_{2} \mathrm{O}_{3}$ catalyst are surrounded by sulfur ions $[34,35]$. However, no second shell of neighboring ions can be determined, indicating that the cobalt ions are not present in a unique, well-ordered structure. Farragher suggested that the cobalt ions at the $\mathrm{MoS}_{2}$ edges are located between subsequent $\mathrm{MoS}_{2}$ layers, and he therefore called this a pseudointercalation structure, to differentiate it from real intercalation in which the cobalt ions would be randomly distributed between alternate $\mathrm{MoS}_{2}$ layers. Previously, intercalation proper had been suggested by Voorhoeve to be the structure of the cobalt [17]. On the other hand, Topsøe and Topsøe claimed that the cobalt ions are located at the edges of the molybdenum plane of a $\mathrm{MoS}_{2}$ layer, therefore extending the $\mathrm{MoS}_{2}$ layer. Convincing evidence for this model came from an infrared study of the adsorption of NO molecules 
on a series of sulfided $\mathrm{Co}-\mathrm{Mo} / \mathrm{Al}_{2} \mathrm{O}_{3}$ catalysts [36]. The IR spectrum of NO molecules adsorbed on cobalt ions can be distinguished from that of NO molecules on molybdenum ions. By increasing the cobalt loading at fixed molybdenum loading it was demonstrated that the spectrum of NO adsorbed on Co sites increased in intensity, while that of NO adsorbed on Mo sites decreased in intensity. If the cobalt ions had been in the location proposed by Farragher, the intensity of the NO on Co spectrum should have increased, but the intensity of the NO on Mo spectrum should have stayed constant. Cobalt ions in the locations proposed by Topsøe and Topsøe, however, cover molybdenum ions and block adsorption of NO on these Mo ions. Therefore the observed behavior is in accordance with the Colocation proposed by Topsøe and Topsøe [36]. A point that should be studied further is whether NO molecules actually chemisorb on the catalyst surface without disturbing its structure. If corrosive chemisorption were indeed to occur. the conclusions drawn from the IR adsorption study would need reinterpretation.

Both Farragher and Topsøe et al. describe the environment of the cobalt ions in terms of octahedral or trigonal prismatic holes. Recently, Ledoux has suggested on the basis of solid-state NMR work that the cobalt ions may indeed be situated in tetrahedral positions at the $\mathrm{MoS}_{2}$ edges [37].

Kasztelan et al. have quantitatively considered the solid-state structure of $\mathrm{MoS}_{2}$ and the edge location of the cobalt promoter by calculating the number of edge and corner Mo and Co sites as a

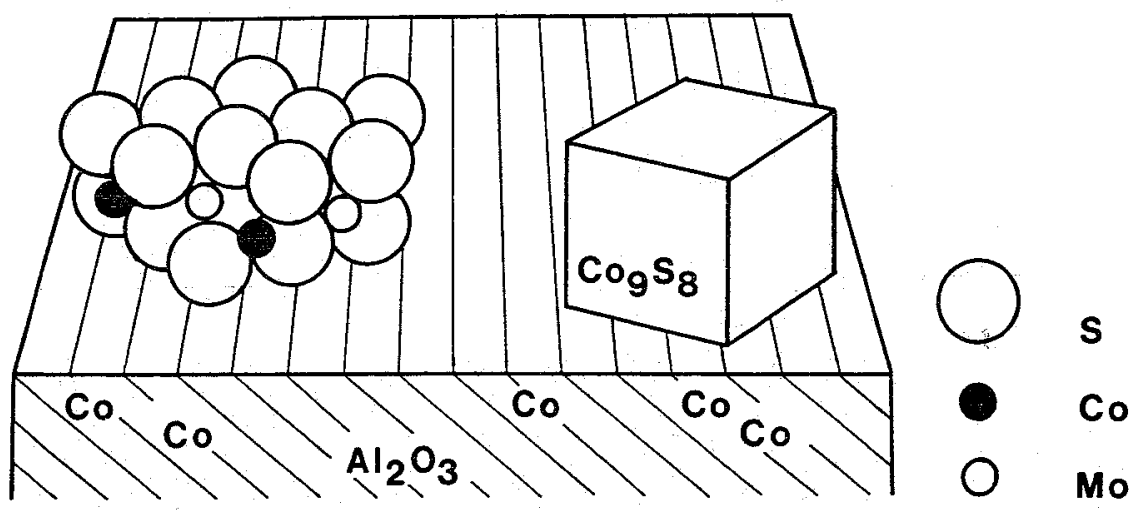

FIG. 2. Structures of the different forms in which cobalt ions can be present in Co-promoted $\mathrm{MoS}_{2} / \mathrm{Al}_{2} \mathrm{O}_{3}$. 
function of $\mathrm{MoS}_{2}$ particle size [38]. Several geometries for a single $\mathrm{MoS}_{2}$ slab were taken into consideration. The reasonable fit between predictions and experimental results indicates that the assumptions underlying the model are not unrealistic.

In summary, the structure of a sulfided $\mathrm{Co}-\mathrm{Mo} / \mathrm{Al}_{2} \mathrm{O}_{3}$ catalyst consists of small $\mathrm{MoS}_{2}$ crystallites which either lie with their basal planes parallel to the $\mathrm{Al}_{2} \mathrm{O}_{3}$ surface or are edge-bonded to the $\mathrm{Al}_{2} \mathrm{O}_{3}$ surface (cf. Fig. 1). The majority of the cobalt is present as cobalt ions adsorbed on the edges of the $\mathrm{MoS}_{2}$ crystallites and as $\mathrm{Co}_{9} \mathrm{~S}_{8}$ crystallites on the $\gamma-\mathrm{Al}_{2} \mathrm{O}_{3}$ surface. $\mathrm{A}$ high $\mathrm{Co} / \mathrm{Mo}$ ratio and a high sulfidation temperature of the oxidic precursor favor $\mathrm{Co}_{9} \mathrm{~S}_{8}$ formation; however, some cobalt is always present in tetrahedral sites in the $\mathrm{Al}_{2} \mathrm{O}_{3}$ lattice. A schematic picture of the resulting structure is presented in Fig. 2.

\section{MODELS OF THE HDS REACTION MECHANISMS OVER THE Mo-S/ $/ \gamma-\mathrm{Al}_{2} \mathrm{O}_{3}$ SYSTEM AND EXPERIMENTAL VERIFICATIONS}

\section{A. Solid-State Model}

Solid-state chemistry models for sulfidic HDS catalysts were first proposed by Voorhoeve [17] and by Farragher and Cossee [26, 32]. They explained their experimental results for the hydrogenation of benzene and cyclohexene by assuming that the catalytically active site was a Mo ion located at the edge of a $\mathrm{MoS}_{2}$ crystallite. As in ZieglerNatta research, where it had been found that the basal planes of $\mathrm{TiCl}_{3}$ crystallites are inactive [39], they assumed that in $\mathrm{MoS}_{2}$ (which like $\mathrm{TiCl}_{3}$ has a layer lattice structure) the sulfur anions in the basal planes are strongly bonded and are difficult to remove so that a sulfur vacancy may be created and expose a Mo ion. As indicated in Section II.A, recent experiments have proved this assumption to be valid.

In the solid-state model the desulfurization starts by adsorption of the sulfur atom of the reactant molecule on the sulfur vacancy. A four-electron reduction process $[6,40]$ then leads to the formation of $\mathrm{H}_{2} \mathrm{~S}$ and butadiene from thiophene:

$$
\begin{aligned}
\mathrm{C}_{4} \mathrm{H}_{4} \mathrm{~S}+\square+2 \mathrm{H}^{+}+4 \mathrm{e} & \rightarrow \mathrm{C}_{4} \mathrm{H}_{6}+\mathrm{S}^{2-} \\
2 \mathrm{H}_{2} & \rightarrow 4 \mathrm{H}^{+}+4 \mathrm{e} \\
\mathrm{S}^{2-}+2 \mathrm{H}^{+} & \rightarrow \square+\mathrm{H}_{2} \mathrm{~S}
\end{aligned}
$$


The four electrons are delivered by a redox couple like

$$
4 \mathrm{Mo}^{n+} \rightarrow 4 \mathrm{Mo}^{(n+1)+}+4 \mathrm{e}
$$

or

$$
2 \mathrm{Mo}^{n+} \rightarrow 2 \mathrm{Mo}^{(n+2)+}+4 \mathrm{e}
$$

Looking at these reactions in a different way

$$
\mathrm{H}_{2}+\mathrm{Mo}^{(n+2)+}+\mathrm{S}^{2-} \rightarrow \mathrm{H}_{2} \mathrm{~S}+\mathrm{M}^{n+}
$$

we might say that hydrogen is used in a reductive addition reaction on sulfidic surfaces, as on some oxidic surfaces [41]. Written in this way, the HDS reaction clearly has much in common with the Birch reduction of functional groups in organic molecules in a solution of $\mathrm{Na}$ or $\mathrm{K}$ in liquid $\mathrm{NH}_{3}$, in which the reduction is not performed by hydrogen atoms, but by electrons and protons. Under the high $\mathrm{H}_{2}$ pressure conditions during HDS, transition metal sulfides become sulfur deficient and good electron conductors. Protons are always available at the surface of transition metal sulfides in the form of SH groups. The analogy with the Birch reduction explains the observations made by Pecoraro and Chianelli [42], Vissers et al. [43], and Ledoux et al. [44] that most transition metal sulfides are capable of catalyzing the HDS reaction.

When the reactant thiophene molecule is assumed to adsorb upright on the surface, the so-called one-point (end-on) mechanism for the HDS of thiophene is obtained [45]. This mechanism is shown in Fig. 3.

An objection to the end-on mode of adsorption has been that the basicity of the sulfur atom in thiophene is low, due to the delocalization of the lone pair electrons on sulfur onto the butadiene fragment in thiophene [46]. Thus Budzelaar was able to synthesize a binuclear molybdenum complex in which tetrahydrothiophene is bridge bonded between two Mo atoms (with the tetrahydrothiophene plane perpendicular to the Mo-S-Mo plane), but he was unable to prepare the corresponding thiophene complex [47]. To overcome the problem of low basicity on the sulfur atom, Kwart et al. proposed that adsorption of thiophene takes place via "multipoint" (side-on) adsorption [46]. In this mechanism, the $\mathrm{C}_{1}-\mathrm{C}_{2}$ bond of thiophene is coordinated at a sulfur anion vacancy, with the adjacent sulfur atom interacting with a neighboring sulfur ion at the catalyst surface. The first steps of the HDS mechanism are suggested to take place as shown in Fig. 4. 


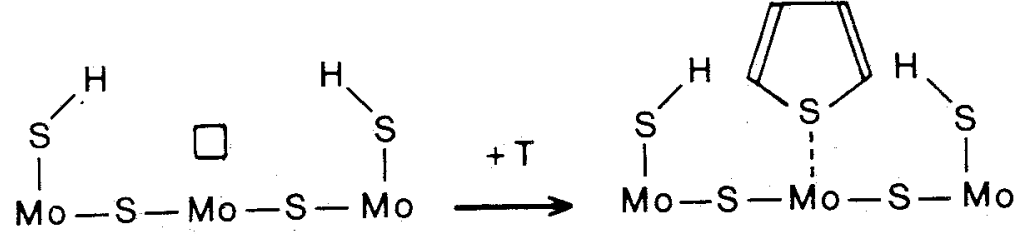<smiles>[M]O[SH](OC)S/C=C\C=C/S</smiles><smiles>C=C/C=C\C</smiles>

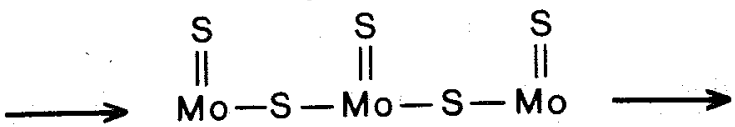<smiles>CC[As](=S)O[As](=S)OC</smiles><smiles>[H][M](OCSOC)O[SiH2]C</smiles><smiles>COSNO[M]O[Si]</smiles>

FIG. 3. End-on mechanism for the hydrodesulfurization of thiophene on the edge surface of $\mathrm{MoS}_{2}$.

The assistance of an adjacent sulfur atom in the side-on mechanism leads to sulfur-sulfur bond formation, and suggests that persulfide $S_{2}^{2-}$ anions may be of importance in HDS. As a consequence of lower coordination, the Madelung energy of surface ions is lower than that 


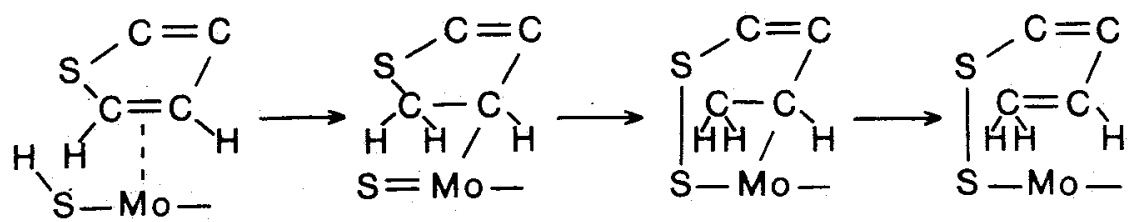

FIG. 4. Side-on mechanism for the hydrodesulfurization of thiophene on the edge surface of $\mathrm{MoS}_{2}$.

of bulk ions and the oxidation state will therefore be lower. The surface of $\mathrm{MoS}_{2}$ thus contains $\mathrm{S}_{2}^{2-}$ anions [48]. The involvement of such persulfide anions in HDS has already been proposed $[49,50]$. It is noteworthy that $\mathrm{RuS}_{2}$ and $\mathrm{OsS}_{2}$, which have the pyrite crystal structure with $\mathrm{S}_{2}^{2-}$ units, are among the very best HDS catalysts, and that $\mathrm{Co}, \mathrm{Ni}$, and $\mathrm{Fe}$, which are known promoters for $\mathrm{MoS}_{2}$, can also occur in the pyrite structure.

\section{B. Organometallic Chemistry Models}

Organometallic chemistry can be of help to heterogeneous catalysis in two ways. First, it can identify which types of adsorbate-substrate structures are possible; and second, it can provide information on the reactivity of such structures [51]. Knowledge of these structures and their reactivities can aid in choosing between alternative models for catalytic reactions, although the "translation" from an organometallic complex-with the metal atom in a formal oxidation state and with phosphine, carbon monoxide, and/or cyclopentadienyl ligands to a metal ion at a metal sulfide surface-is not always straightforward.

Thiophene has proved to be a versatile ligand in bonding to metal atoms. Sulfur bonded, $\eta^{\prime}$-carbon bonded, $\eta^{2}$-carbon bonded, and $\eta^{5}$-bonded $(\pi$-bonded) complexes have been synthesized for thiophene (Refs. 52-54, and references therein). For benzothiophene and dibenzothiophene $\eta^{6}$-bonded complexes have also been reported, in which the benzene ring is $\pi$-bonded to the metal atom instead of the thiophene ring $[55,56]$. Only a few S-bonded transition metal-thiophene complexes are known, and in these the thiophene ligand can be readily replaced by weakly coordinating ligands $[53,57,58]$. Incorporation of thiophene into a chelating ligand has led to increased stability of the $S$-bonded structure [59], but such chelate ligands are only indirectly related to HDS substrates. Partial or total hydrogenation of the thiophene rings leads to decreased $\pi$-resonance and 
increased basicity of the sulfur atom. As a consequence, 2,3-dihydrothiophene [60) and tetrahydrothiophene [47] form much stronger S-bonded complexes than thiophene. Many thiophene complexes are known in which the thiophene molecule is $\pi$-bonded to the metal atom (see references in Refs. 52, 53, and 59). The slow transformation of $\left[\left(\eta^{1}-\mathrm{S}-\mathrm{C}_{4} \mathrm{H}_{4} \mathrm{~S}\right) \mathrm{Fe}\left(\mathrm{C}_{5} \mathrm{H}_{5}\right)\left(\mathrm{P} \phi_{3}\right)_{2}\right] \mathrm{BF}_{4}$ into $\left[\left(\eta^{5}-\mathrm{C}_{4} \mathrm{H}_{4} \mathrm{~S}\right)-\right.$ $\left.\mathrm{Fe}\left(\mathrm{C}_{5} \mathrm{H}_{5}\right)\right] \mathrm{BF}_{4}$ demonstrates that a S-bonded thiophene molecule can transform into a $\pi$-bonded molecule [59]. Recently, Angelici and co-workers proposed that thiophene also adsorbs to HDS catalysts in the $\pi$-bonded form and extensively studied the reactivity of $\pi$ bonded thiophene complexes of $\mathrm{Mn}$ and $\mathrm{Ru}$. The $\left(\pi-\mathrm{C}_{4} \mathrm{H}_{4} \mathrm{~S}\right) \mathrm{Mn}(\mathrm{CO})_{3}^{+}$ complex was found to add nucleophiles like $\mathrm{CN}^{-}, \mathrm{CH}_{3} \mathrm{O}^{-}, \mathrm{RS}^{-}$, and $\mathrm{H}^{-}$to the $\alpha$-carbon atom adjacent to the sulfur atom [52]:
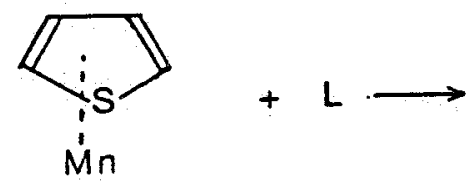

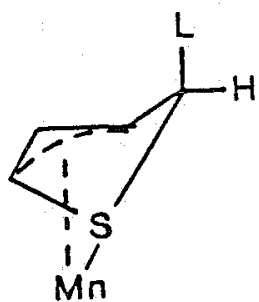

$e \times 0$

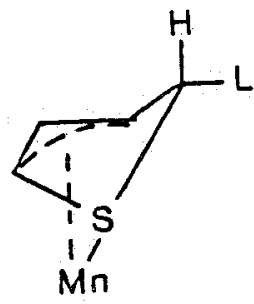

endo

To model the hydrogenation of thiophene in HDS, Angelici et al. reacted $\left(\pi-\mathrm{C}_{4} \mathrm{H}_{4} \mathrm{~S}\right) \mathrm{Mn}(\mathrm{CO})_{3}^{+}$with $\mathrm{DFe}(\mathrm{CO})_{4}^{-}$and observed that $\mathrm{D}^{-}$ adds to both the exo and endo sides of the thiophene ring [61]. Hydride transfer to $\left(\eta^{5}-2\right.$-methylthiophene $) \mathrm{Mn}(\mathrm{CO})_{3}^{+}$occurred exclusively to the nonmethylated carbon atom $\mathrm{C}_{5}$ :
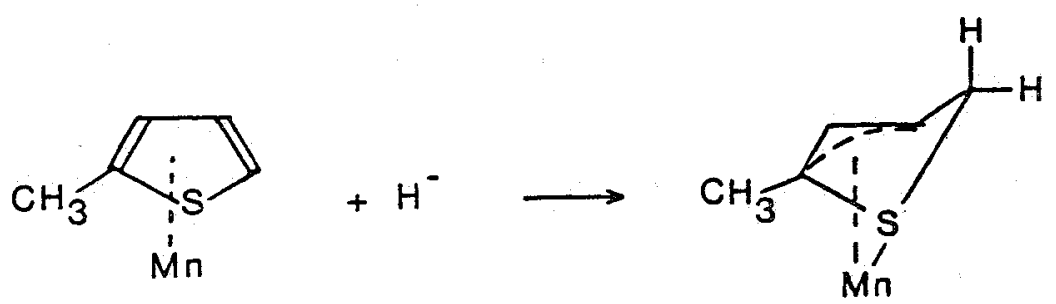

Further hydrogenation of the thiophene ligand in the manganese complex could be accomplished by addition of a proton, by bubbling $\mathrm{HCl}$ gas through a solution of (thiophene $\cdot \mathrm{H}) \mathrm{Mn}(\mathrm{CO})_{3}[52]$. Although 
the resulting complex could not be identified unequivocally, it was clear that 2,3-dihydrothiophene had been formed.

These reactivity studies demonstrate that thiophene in $\left(\mathrm{C}_{4} \mathrm{H}_{4} \mathrm{~S}\right) \mathrm{Mn}(\mathrm{CO})_{3}^{+}$is activated to react with nucleophiles under mild conditions. The addition of a nucleophile to the $\alpha$-carbon atom breaks the aromatic stabilization of the thiophene ring, weakens the $\mathrm{C}-\mathrm{S}$ bond and opens the way to sulfur removal from the thiophene molecule. Consecutive addition of a hydride ion and a proton leads to a complex with S-bonded 2,3-dihydrothiophene as a ligand. On the surface of a real HDS catalyst the hydride may be supplied by a molybdenum or cobalt atom, and the proton from a surface $\mathrm{SH}$ group $[52,61]$. It is questionable, however, if hydride ions exist on the Mo or $\mathrm{Co}$ atom in metal sulfide surfaces. An alternative way to break the aromaticity of the thiophene ring would be the addition of a $\mathrm{SH}^{-}$ group to thiophene, followed by protonation, leading to 2,3-dihydro2-mercaptothiophene.

The second-row transition-metal complex $\left(\eta^{5}-\mathrm{C}_{4} \mathrm{H}_{4} \mathrm{~S}\right) \mathrm{Ru}\left(\mathrm{C}_{5} \mathrm{H}_{5}\right)^{+}$ demonstrated even more exciting chemistry. Addition of nucleophiles as $\mathrm{H}^{-}$[62] and $\mathrm{CH}_{3} \mathrm{O}^{-}$and $\mathrm{CH}_{3} \mathrm{~S}^{-}$[63] to this complex led not only to addition to the $\alpha$-carbon atom, but also to simultaneous cleavage of the $\mathrm{C}-\mathrm{S}$ bond to give a butadienethiolate ligand, coordinated through sulfur and all four unsaturated carbon atoms. The butadiene ligand fragment could be replaced by phosphines, leaving the butadienethiolate ligand coordinated only via the sulfur atom:

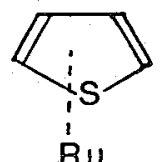

$\mathrm{Ru}$
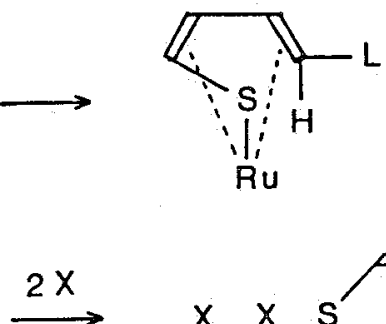

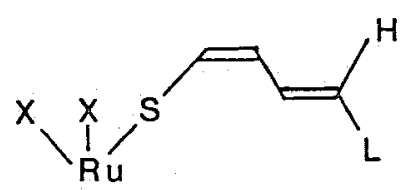

As was the case for the $\left(\mathrm{C}_{4} \mathrm{H}_{4} \mathrm{~S}\right) \mathrm{Mn}(\mathrm{CO})_{3}^{+}$complex, initial nucleophilic attack on the $\left(\mathrm{C}_{4} \mathrm{H}_{4} \mathrm{~S}\right) \mathrm{Ru}\left(\mathrm{C}_{5} \mathrm{H}_{5}\right)^{+}$complex may give an allyl sulfide intermediate, and this intermediate may undergo $\mathrm{C}-\mathrm{S}$ bond cleavage to the butadienethiolate complex. Differences in stability of the butadienethiolate manganese and ruthenium complexes might then 
explain why the ruthenium intermediate, but not the manganese intermediate, undergoes $\mathrm{C}-\mathrm{S}$ bond cleavage.

On a HDS catalyst surface, the nucleophilic attack may be carried out by a $\mathrm{M}-\mathrm{S}^{-}$group, leading to a butadienedithiolate [63].<smiles>[M][As]1C=CC=C1</smiles>

$+$<smiles>[M]S</smiles><smiles>[CH]C</smiles>

$M$

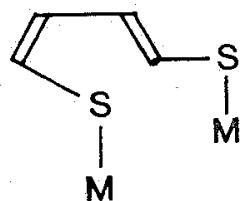

M

Like other mercaptans, the butadienedithiolate should undergo desulfurization much more readily than thiophene. This desulfurization may follow a route proposed for vinylthiolate molybdemum complexes by Rakowski DuBois and co-workers. They showed that a vinylthiolate Mo complex reacts with $\mathrm{H}_{2}$ to cleave the $\mathrm{C}-\mathrm{S}$ bond [64]:

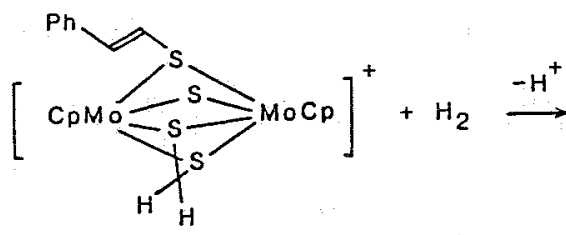

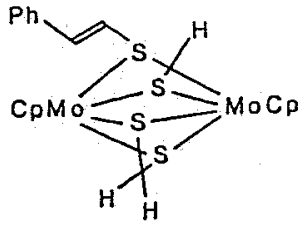

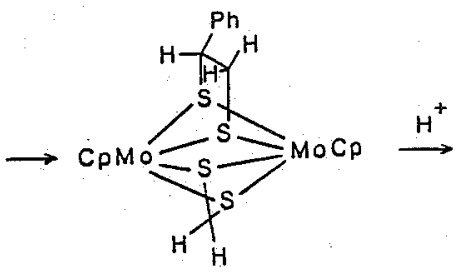

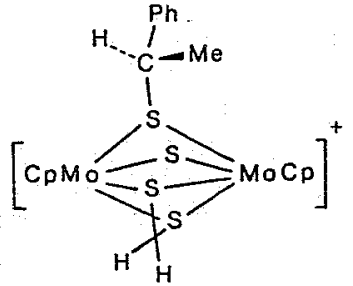

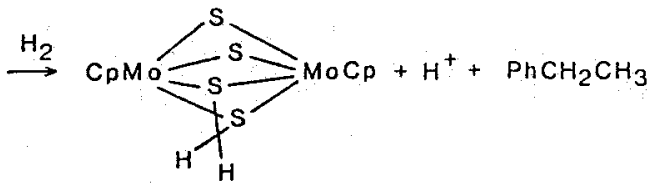


The studies of Angelici and co-workers thus demonstrate that the mechanism of hydrogenolysis of the $\mathrm{C}-\mathrm{S}$ bond on the catalyst surface may involve $\pi$-bonding, rather than S-bonding, of thiophene to a metal ion. Additionally, the fact that the rate of HDS of $\alpha$-methylsubstituted thiophene is not much smaller than that of thiophene is consistent with a $\pi$-bonding model [61]. In the case of S-bonding one would have predicted a decrease of several orders of magnitude in the rate of HDS due to steric hindrance by the $\alpha$-methyl group(s) [46]. The $\pi$-bonded structure may also account for the observed preferential $\mathrm{H}-\mathrm{D}$ exchange of the $\alpha-\mathrm{H}$ atoms of thiophene, when $\mathrm{D}_{2}$ and thiophene are passed over HDS catalysts. 'H-NMR studies demonstrate that the $\alpha-\mathrm{H}$ atoms of thiophene in $\left(\mathrm{C}_{4} \mathrm{H}_{4} \mathrm{~S}\right) \mathrm{Ru}\left(\mathrm{C}_{5} \mathrm{H}_{5}\right)^{+}$readily undergo exchange in the presence of bases such as $\mathrm{KOH}$ or $\mathrm{Al}_{2} \mathrm{O}_{3}$, while the exchange of the $\beta-\mathrm{H}$ atoms is much smaller $[65,66]$.

Organometallic equivalents of the suggested elementary reaction steps in HDS have also been studied by Rakowski DuBois and coworkers. They studied the reaction of dihydrogen and unsaturated hydrocarbons with sulfido-bridged dimers of cyclopentadienyl molybdenum. Dihydrogen could be activated by reductive addition to form $\mu$-hydrosulfido ligands [67]:

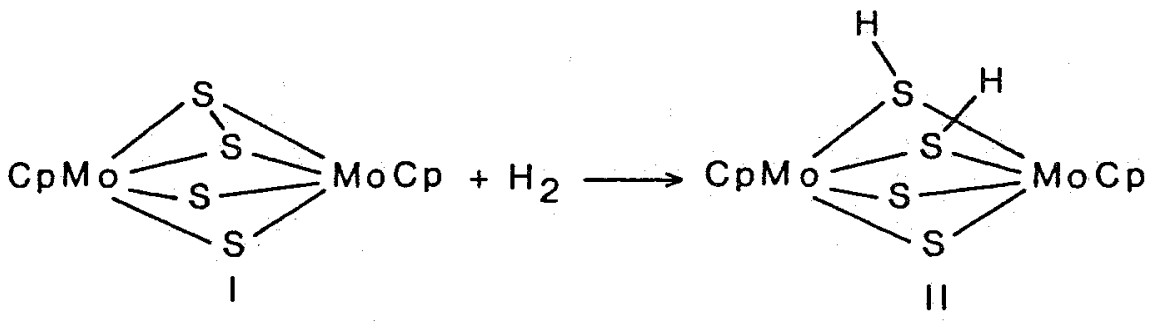

The hydrosulfido complex II was observed to catalyze the reduction of elemental sulfur to hydrogen sulfide [67], probably by the formation of persulfide complexes [68]:

4

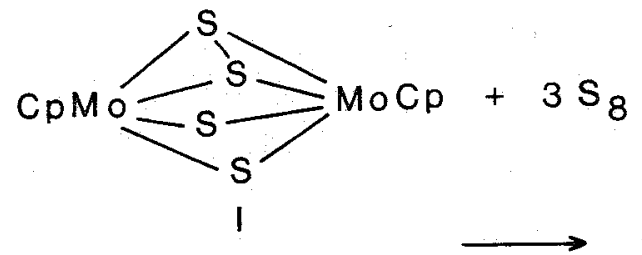

4

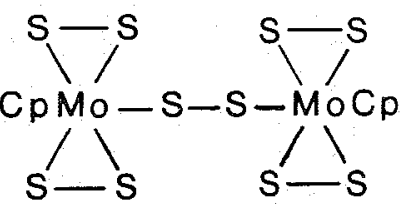

III 
and subsequent hydrogen transfer

$$
\begin{aligned}
& 6 \mathrm{I}+6 \mathrm{H}_{2} \rightarrow 6 \mathrm{II} \\
& 6 \mathrm{II}+\mathrm{III} \rightarrow 7 \mathrm{I}+6 \mathrm{H}_{2} \mathrm{~S}
\end{aligned}
$$

Adsorption of an organosulfur compound and subsequent hydrogenolysis of a carbon-sulfur bond was demonstrated for carbon disulfide [69]:

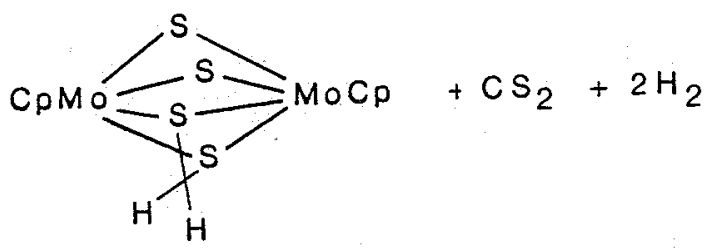

IV

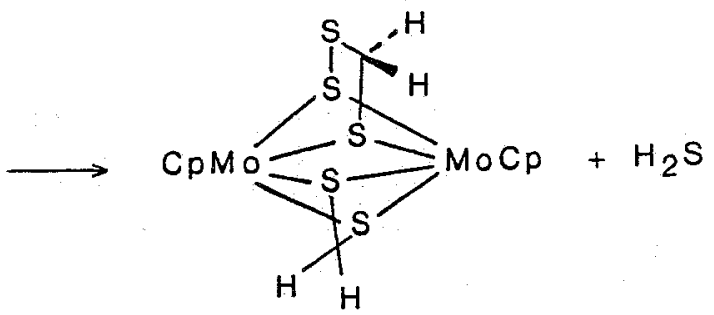

This reaction, which proceeds under the mild conditions of $75^{\circ} \mathrm{C}$ and $2 \mathrm{~atm} \mathrm{H}_{2}$, involves the initial conversion of $\mathrm{CS}_{2}$ to $\mathrm{H}_{2} \mathrm{~S}$ and thioformaldehyde $\mathrm{CH}_{2} \mathrm{~S}$, as proven by the formation of the thioformaldehyde complex from formaldehyde and $\mathrm{H}_{2} \mathrm{~S}$.

Many unsaturated molecules can add to two adjacent $\mu$-sulfido ligands in the dimeric molybdenum complexes $[67,70]$. For example, an alkyne adds as follows:

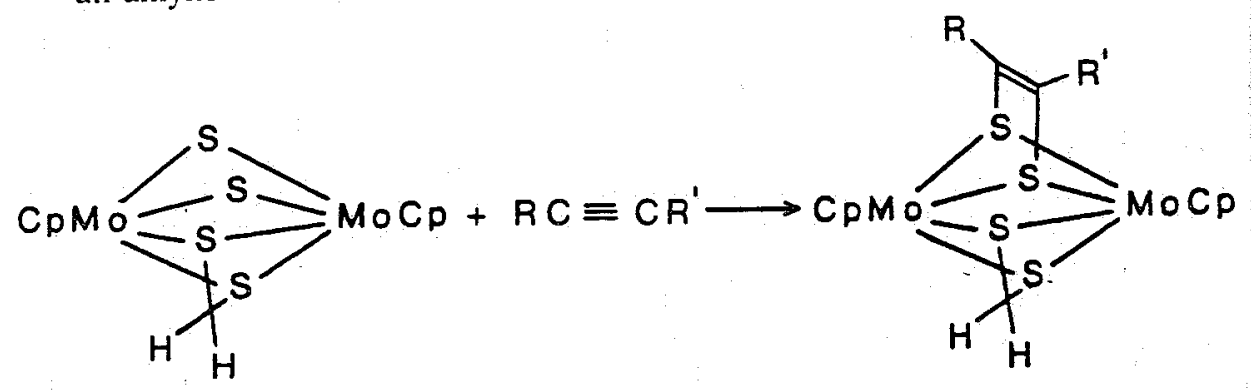


This alkyne adduct undergoes hydrogenation and hydrogenolysis of two $\mathrm{C}-\mathrm{S}$ bonds under mild conditions, $1 \mathrm{~atm} \mathrm{H}_{2}$ and $60^{\circ} \mathrm{C}$, under reformation of the original dimeric molybdenum complex [70]:
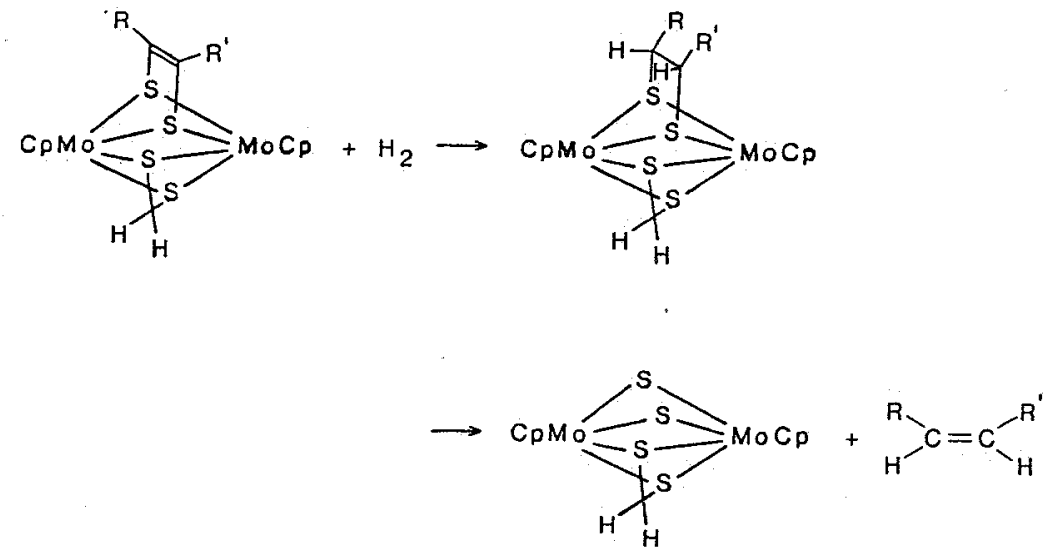

In principle, the addition of alkyne and its subsequent hydrogenation form a catalytic cycle, but since excess substrate inhibits hydrogenation, the reaction of alkyne to alkene does not proceed in a continuous catalytic cycle. The reduction of the alkyne adduct is stereoselective, since only cis-alkene is produced.

The complexes $\mathrm{CpMo}(\mu-\mathrm{S})_{2}\left(\mathrm{~S}_{2} \mathrm{CH}_{2}\right) \mathrm{MoCp}(\mathrm{IV})$ and $\mathrm{CpMo}(\mu-$ $\mathrm{S}_{2}(\mathrm{SH})_{2} \mathrm{MoCp}(\mathrm{II})$ serve as homogeneous catalysts for the hydrogen reduction of several other unsaturated molecules, such as azides, azobenzene, imines, isocyanates, and nitrobenzenes [71]. The mechanism may in all cases be similar to the one for azobenzene:

$$
\begin{aligned}
& I+\mathrm{H}_{2} \rightarrow \text { II } \\
& \mathrm{II}+\mathrm{I}_{\mathrm{N}=\mathrm{N}} \mathrm{Ph}_{\mathrm{Ph}} \longrightarrow \mathrm{I}+\mathrm{H}_{\mathrm{N}-\mathrm{N}^{\prime}}^{\mathrm{Ph}}
\end{aligned}
$$

Concerning the oxidation state of molybdenum on the HDS catalyst surface, Rakowski DuBois et al. observed that dimeric Mo(IV)-Mo(IV) complexes could be easily reduced in two successive one-electron steps and that the resulting Mo(III)-Mo(III) complexes had interesting chemical properties $[72,73]$. The $\mathrm{CpMo}\left(\mathrm{S}_{2} \mathrm{CH}_{2}\right)(\mu$ $\left.\mathrm{SCH}_{3}\right)(\mu-\mathrm{SH}) \mathrm{MoCp}$ complex therefore reacted with activated alkynes 
and alkenes by insertion into the SH ligand bond to form alkenyl or alkyl thiolate ligands.
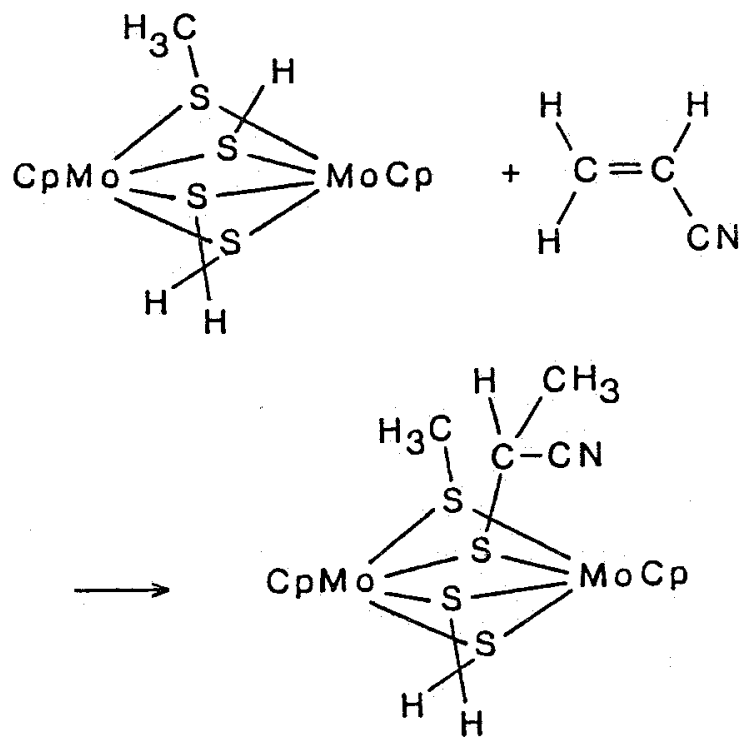

Such insertion reactions may serve as a model for the participation of hydrosulfide groups in hydrogenation [73].

Hydrogen activation by reductive addition to the $\mu$-sulfido ligand is thus a viable reaction in organometallic chemistry just as in solid-state chemistry (compare Section III.A), and so is the hydrogen atom transfer to adsorbed unsaturated molecules. However, cleavage of a $\mathrm{C}-\mathrm{S}$ bond has so far been observed only for $\mathrm{CS}_{2}$ and for alkene adducts of $\mathrm{CpMo}(\mu-\mathrm{S})_{2}\left(\mathrm{SCH}_{2}\right) \mathrm{MoCp}$, perhaps due to the lack of vacant coordination sites for bonding of an organosulfur compound. The basicity of the organosulfur molecule also may be of importance.

The bonding of unsaturated molecules via a sulfur ligand, rather than via a molybdenum atom, is governed by the absence of a vacant coordination site. In the study of organometallic models for FischerTropsch reactions, it was discovered that small metal clusters suffer from strong bonding of the ligands. Dissociation equilibria for ligands attached to small metal clusters are unfavorable for dissociation. The coordination of organosulfur molecules to molybdenum may prove difficult in molybdenum complexes, and as a consequence hydrogenolysis of the $\mathrm{C}-\mathrm{S}$ bond will be observed only in rare cases. On the other hand, even small clusters may be very valuable model com- 
pounds, since solid-state chemistry (Section III.A) and surface science studies (Section III.C) indicate that the catalytic HDS chemistry might take place in the second, rather than in the first, coordination shell of the molybdenum atom. Consequentially, organometallic $\mathrm{Mn}$ and $\mathrm{Ru}$ chemistry suggests that thiophene may well be $\pi$-bonded rather than S-bonded on the HDS catalyst surface. Addition of a nucleophile to $\pi$-bonded thiophene leads to decreased $\pi$-resonance and to the formation of S-bonded 2,3-dihydrothiophene or butadienethiolate, both of which can be rather easily desulfurized. However, for such a $\pi$ bonding of thiophene to occur on the surface of $\mathrm{MoS}_{2}$, there should be three sulfur vacancies around the Mo atom to adsorb the thiophene molecule. More vacancies may be even needed for $\pi$-bonding of (di)benzothiophene. Only Mo atoms at corners may have that many vacancies. Alternatively, organometallic Mo chemistry indicates that several reaction steps of relevance to HDS may take place on sulfur ions, in the second coordination sphere of the molybdenum cations.

\section{Surface Science Model}

Surface science studies of the structure of adsorbates on metal single-crystal surfaces and of their desorption and decomposition characteristics, and especially studies of catalytic reactions on such single-crystal surfaces at elevated pressures, have in the last decade provided a wealth of information on catalytic reactions on metals [74]. In the light of this success it was not too surprising that also oxide and sulfide surfaces were studied. However, Salmeron et al. found no activity when the basal planes of a $\mathrm{MoS}_{2}$ single crystal were exposed to thiophene, butadiene, or $\mathrm{H}_{2} \mathrm{~S}$ at low pressure [18]. In accordance with other studies $[17,32]$, this lack of activity was attributed to the strong bonding of sulfur anions in the basal planes to the molybdenum cations in the layered $\mathrm{MoS}_{2}$ structure. Unfortunately, a $\mathrm{MoS}_{2}$ single crystal with a sizeable and well-defined edge surface is almost impossible to prepare. For that reason Salmeron and Somorjai and coworkers switched to the approach of studying a metal single-crystal surface with adsorbed sulfur as a model catalyst for hydrodesulfurization. In a series of papers $[18,19,75-77]$ they described the results of their studies of temperature-programmed desorption (TDS) of thiophene and other molecules from clean, sulfided, and carbided Mo(100) surfaces. Thiophene, adsorbed on clean Mo(100), decomposed upon heating, leaving carbon and sulfur deposits on the surface. Preadsorbed sulfur blocked the decomposition of thiophene; above 
$\theta_{\mathrm{s}}=0.5$, only associatively chemisorbed (undecomposed) thiophene was observed.

Related studies using edge $\mathrm{X}$-ray absorption [78,79], TDS, and high-resolution electron-energy-loss spectroscopy (HREELS) [80-83] on $\mathrm{Pt}(111),(100)$, and (210); $\mathrm{Mo}(100) ; \mathrm{Ni}(100)$; and $\mathrm{Cu}(100)$ surfaces also demonstrated that thiophene adsorbs dissociatively on clean metal surfaces. Accordingly, analysis of the angular dependence of nearedge $\mathrm{X}$-ray absorption fine structure (NEXAFS) above the $\mathrm{C}$ K-edge of thiophene adsorbed on $\mathrm{Pt}(111)$ revealed that thiophene adsorbs at low temperature, and at monolayer coverage it lies flat on the metal surface [78]. NEXAFS spectra taken above the S L-edge showed that C-S bond breaking commences at $290 \mathrm{~K}$ and is completed by $470 \mathrm{~K}$. HREELS spectra showed that a $\mathrm{Pt}-\mathrm{S}$ stretching vibration appeared at around $350 \mathrm{~K}$, again indicative of $\mathrm{C}-\mathrm{S}$ bond breaking. Furthermore, the HREELS frequencies of the $\mathrm{C}-\mathrm{C}$ and $\mathrm{C}-\mathrm{H}$ modes indicated that the hydrocarbon skeleton remaining after $\mathrm{C}-\mathrm{S}$ bond breaking was largely unchanged from that of thiophene, suggesting that $\mathrm{C}_{4} \mathrm{H}_{4}$ was bonded to the metal surface by incorporation of a $\mathrm{Pt}$ atom to form a metallocycle. Recently Lang and Masel have rejected the formation of a true metallocycle on the grounds that structure sensitivity in the XPS and TDS spectra of thiophene adsorbed on $\mathrm{Pt}(111),(100)$, and (210) surfaces was not observed [80]. They reasoned that formation of a true metallocycle, as opposed to a multiple-bonded species, requires replacement of the sulfur atom in the thiophene ring by a metal atom. Consequently, removal of a surface metal atom from an open surface will be easier than removal from a closed packed surface. Their XPS S2p spectra again demonstrated that thiophene loses sulfur around $350 \mathrm{~K}$, and furthermore they concluded that no desulfurization (and only desorption) occurs when heating thiophene adsorbed on a fully sulfided surface.

Zaera et al. observed a strong dependence of the thiophene decomposition on the total coverage on the metal surface [79]. They performed a combined TDS and HREELS study of the decomposition of thiophene on $\mathrm{Mo}(100)$ by taking HREELS spectra at intervals of $20 \mathrm{~K}$. At low thiophene coverage only one $\mathrm{H}_{2}$ TDS peak was observed around $340 \mathrm{~K}$, while the HREELS spectra showed that a $\mathrm{C}-\mathrm{H}$ stretch mode of thiophene at $3040 \mathrm{~cm}^{-1}$ disappeared at $310 \mathrm{~K}$. Analysis of the HREELS frequencies suggested that the final carbonaceous residue lies flat on the surface. Complete dehydrogenation was achieved by $410 \mathrm{~K}$. At high thiophene coverage the thiophene most probably adsorbs with the ring perpendicular to the surface, with the $\mathrm{S}$ atom down. In this case a sequential dehydrogenation starts with $\mathrm{C}-\mathrm{H}$ 
bond breaking in the $\alpha$-position. By $500 \mathrm{~K}$ a stable $\mathrm{C}_{4} \mathrm{H}_{2} \mathrm{~S}$ fragment is formed on the surface, which loses sulfur about $600 \mathrm{~K}$.

All these studies of thiophene adsorption and decomposition on different metal surfaces demonstrate that $\mathrm{C}-\mathrm{S}$ bond breaking precedes $\mathrm{C}-\mathrm{C}$ bond breaking. Eventually a $\mathrm{C}_{4} \mathrm{H}_{x} \mathrm{M}$ metallocycle-like species is formed. Its stoichiometry depends on the dehydrogenation activity of the metal substrate ( $x=4$ for $\mathrm{Pt}, 3$ for $\mathrm{Ni}$, and 2 for $\mathrm{Mo}$ ). At low coverage thiophene usually adsorbs flat on the metal surface, while at high coverage it adsorbs perpendicular to the surface, or in a somewhat tilted configuration.

TDS of tetrahydrothiophene and butanethiol on Mo(110) was studied by Roberts and Friend [84]. For both adsorbates the same butylthiolate intermediate was found, which gave either butane by hydrogenation at the $\mathrm{C}_{\alpha}$ position or butene by $\beta-\mathrm{H}$ elimination. Benziger and Preston studied the TDS of methanethiol and methanol on clean, oxidized, carbided, and sulfided W(211) surfaces [85]. In accordance with the studies previously discussed, they observed strong decomposition on a clean surface and blocking of decomposition on the other surfaces. In their view, a clean metal surface can be seen as a strong reducing agent which completely decomposes the adsorbate to form a metal oxide, carbide, or sulfide. Partial oxidation of the metal surface with oxygen, carbon, or sulfur reduces the surface reduction potential and stabilizes $\mathrm{CH}_{3}-\mathrm{O}$ and $\mathrm{CH}_{3}-\mathrm{S}$ intermediates. Benziger and Preston also observed a fundamental difference between the adsorption behavior of methanethiol and methanol. Whereas oxygen deposition on the surface diminished the decomposition of both adsorbates, sulfur deposition only diminished the decomposition of methanol, while methanethiol readily adsorbed on sulfided (and also carbided) surfaces. The authors suggested that an alkanethiol adsorbs by disulfide formation: $\mathrm{W}=\mathrm{S}+\mathrm{CH}_{3} \mathrm{SH} \rightarrow \mathrm{W}-\mathrm{S}-\mathrm{S}-\mathrm{CH}_{3}+\mathrm{H}_{\text {ad. }}$.

Thermodynamic arguments were presented to support this suggestion. This model can be viewed as the surface science analogy of the solid-state chemistry suggestions made by Kwart et al. [46], Goodenough [48], and others [49, 50] (cf. Section III.A).

Although Benziger and Preston describe the metal surface as electron donating [85], they further suggest that the metal surface may act as an electrophile (accepting electrons) in the hydrodesulfurization reaction $[86,87]$. Electrophilic attack on the $\alpha$-carbon atom in the thiophene ring leads to loss of $\pi$-resonance and destabilization of the thiophene ring. Subsequent $\mathrm{C}-\mathrm{S}$ bond scission and formation of a $\mathrm{M}-\mathrm{S}$ bond leads to desulfurization. Benziger et al. indicated that the highest occupied molecular orbital of thiophene has the highest elec- 
tron density on the $\alpha$-carbon atom and that sulfur anion vacancies would promote electrophilic reactions because of their electron deficiency. Furthermore, the poisoning of HDS by Lewis bases such as ammonia and pyridine would also point to the importance of surface Lewis acidity [86]. However, although the highest occupied molecular orbital (HOMO) has the highest electron density on the $\alpha$-carbon atoms [88], the same is probably true for the lowest unoccupied molecular orbital (LUMO), since studies of organic reactions of thiophene have shown that electrophilic as well as nucleophilic substitution of thiophene takes place at the $\alpha$ position [89]. This means that the nucleophilic mechanism proposed by Angelici et al. [61$63,65,66]$ is at present as likely as the electrophilic mechanism on the metal surface $[86,87]$.

A series of thiophene desulfurization studies on $\mathrm{Mo}(100)$ singlecrystal surfaces combined with surface science techniques for the characterization of substrate and adsorbates has been carried out by Somorjai and co-workers [90-92]. A great similarity between the properties of this single-crystal surface and supported $\mathrm{MoS}_{2}$ was noted. Thus, there was a similar product distribution between butadiene, butene, and butane [90]; and $\mathrm{H}_{2} \mathrm{~S}$ had a deactivating influence, while butene had no effect on catalytic activity [92]. Radiotracer experiments with ${ }^{35} \mathrm{~S}$ proved that the rate of hydrogenation of deposited sulfur is two orders of magnitude smaller than the turnover frequency of thiophene hydrodesulfurization [91]. This result shows that the reduction of sulfur bound to the metal surface is not a step involved in thiophene hydrodesulfurization over $\operatorname{Mo}(100)$, and that the sulfur removed from thiophene is not deposited in four-fold hollow or bridge sites. ${ }^{14} \mathrm{C}$ radiotracer studies indicated that an initially clean $\mathrm{Mo}(100)$ surface changed into a carbided surface with carbon atoms in the four-fold hollow sites [92]. These adsorbed carbon atoms do not block the active sites for thiophene HDS. Adsorbed sulfur, on the other hand, blocked thiophene HDS. This difference between adsorbed carbon and sulfur was ascribed to the smaller size of the carbon atom, which enables it to sit in the plane of the $M o(100)$ surface, while the larger sulfur atom extends above the metal plane when adsorbed in a four-fold hollow site (cf. Fig. 5).

Four other investigations give support to the idea that the active surface of a HDS catalyst has a carbidic nature. Metal sulfides supported on carbon were observed to have a high HDS activity, much higher than that of the equivalent $\mathrm{Al}_{2} \mathrm{O}_{3}$-supported systems $[49,93,94]$. While the authors ascribed the major part of this enhanced activity to a better dispersion, they also emphasized the 


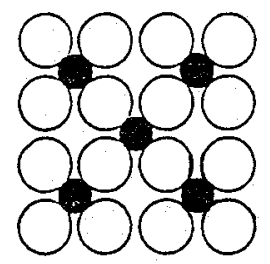

$\theta=0.50 \mathrm{ML}$

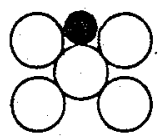

Carbon

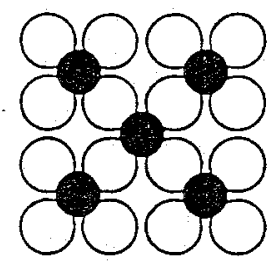

$\theta=0.50 \mathrm{ML}$

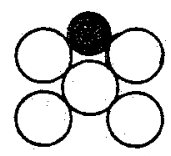

Sulfur

FIG. 5. Schematic diagram of carbon and sulfur atoms adsorbed on the $M o(100)$ surface.

influence of carbon. Metal cations in contact with a soft ligand such as carbon would keep their catalytic activity, while metal cations in contact with a hard base such as the oxygen anion would be inhibited. The previously cited surface science studies on several metal crystal surfaces also showed that while carbon has a moderating influence on a metal surface, oxygen and sulfur strongly decreased the adsorptive and catalytic properties, partly by physical blocking. Also, results described in a patent by Seiver and Chianelli might be taken as evidence for a carbidic catalyst surface [95]. These authors noted that when $\left(\mathrm{NR}_{4}\right)_{2} \mathrm{MoS}_{4}$ was used as a precursor for catalyst preparation, the activity was higher than with catalysts prepared in the conventional way with $\left(\mathrm{NH}_{4}\right)_{6} \mathrm{Mo}_{7} \mathrm{O}_{24}$. During sulfidation and reduction, part of the alkyl groups of the $\mathrm{NR}_{4}$ cation might aid in carbiding the developing. $\mathrm{MoS}_{2}$ surface. From TPD and TPR studies Ramachandran and Massoth have also suggested that a sulfur-containing carbonaceous intermediate may be involved in HDS [96]. Last but not least, Lee and Boudart have demonstrated that the $\mathrm{Mo}_{2} \mathrm{C}$ carbide is about as good a HDS catalyst as $\mathrm{MoS}_{2} / \mathrm{Al}_{2} \mathrm{O}_{3}$ [97].

In view of the similarity between the hydrodesulfurization of thiophene over $\mathrm{Mo}(100)$ and $\mathrm{MoS}_{2}$, Somorjai et al. concluded that also in commercial hydrodesulfurization, the reaction does not take place on 
bare metal sites. They rejected the mechanism proposed by Lipsch and Schuit, in which thiophene adsorbs with its sulfur atom in a sulfur anion vacancy on the $\mathrm{MoS}_{2}$ surface [45]. Furthermore, because of the slow hydrogenation of sulfur adsorbed on the $\mathrm{Mo}(100)$ surface, they proposed that the sulfur from thiophene is never present atomically on the catalyst surface, but that hydrogenation of the sulfur atom in thiophene takes place before the final $C-S$ hydrogenolysis step [92].

Although the similarity in product distribution and in kinetic reactant and product dependence certainly is striking, one may question if a carbided or sulfided surface of a metal single crystal can really be identical to the surface of a metal sulfide. At least two questions may be posed about the comparison of (carbided or sulfided) single crystal surfaces with real supported sulfide catalysts. First, the activity of the single crystals was measured at $1 \mathrm{~atm}$, while the adsorption and characterization studies were performed around $10^{-10}$ Torr. This leaves open the possibility that weakly bound species, which may be of importance in the catalytic study, escape detection in the adsorption studies. If that were the case, however, it would suggest that weakly bound species act as reaction intermediates, probably bound onto the strongly bonded sulfur. Disulfide structures may be such intermediates. A second question involves the fact that metal single-crystal surfaces, whether clean, carbided, or sulfided, do not properly represent the surface of a metal sulfide crystal. Metal sulfides are much more ionic than sulfided or carbided metal surfaces, and in a sulfided or carbided metal surface the metal atoms still have quite a few neighboring metal atoms in their first coordination shell. In a metal sulfide, however, the first coordination shell of a metal cation contains only sulfide anions. For neutrality reasons, in a metal sulfide not all of the surface metal cations can be fully coordinated by sulfur anions, while the metal atoms in the surface of a metal can be fully covered with strongly bonded sulfur. While a metal sulfide thus has surface vacancies by nature, a sulfided metal surface will have no vacancies.

Work of Tatarchuck et al. indicates that there indeed is a difference in catalytic activity between a metal sulfide and a sulfided metal [98]. Tatarchuck et al. studied supported $\mathrm{Ru}$ catalysts which, after impregnation and drying, were reduced before sulfidation. Mild sulfidation of reduced $\mathrm{Ru} / \mathrm{Al}_{2} \mathrm{O}_{3}$ led to sulfidation of only the top layer of the $\mathrm{Ru}$ particles. Rutenium crystallites of $1.8 \mathrm{~nm}$ retained 0.1 monolayer of strongly bound sulfur, while crystallites larger than $3.2 \mathrm{~nm}$ retained 0.25 monolayer. More severe sulfidation (high $\mathrm{H}_{2} \mathrm{~S} / \mathrm{H}_{2}$ ratios and high temperatures) led to completely sulfided $\mathrm{RuS}_{2} / \mathrm{Al}_{2} \mathrm{O}_{3}$ catalysts. Thiophene HDS over the mildly sulfided catalysts proceeded via desul- 
furization of thiophene, followed by hydrogenation of butadiene. Alternatively, over $\mathrm{RuS}_{2} / \mathrm{Al}_{2} \mathrm{O}_{3}$ there was an additional route via hydrogenation to tetrahydrothiophene, followed by desulfurization. Altogether $\mathrm{RuS}_{2} / \mathrm{Al}_{2} \mathrm{O}_{3}$ catalysts were several times more active than sulfided $\mathrm{Ru} / \mathrm{Al}_{2} \mathrm{O}_{3}$ catalysts.

\section{ROLE OF THE COBALT PROMOTER}

\section{A. Co as a Textural Promoter}

The strong increase in the catalytic activity of a $\mathrm{MoS}_{2} / \mathrm{Al}_{2} \mathrm{O}_{3}$ catalyst by addition of $\mathrm{Co}$ or $\mathrm{Ni}$ has been attributed to an increase in the number of Mo sites at the catalyst surface. The role of the promoter then is textural. By altering the texture of the catalyst surface, the promoter creates more active sites, without itself being involved in the catalysis. Accordingly, Voorhoeve proposed that the role of $\mathrm{Ni}$ in the hydrogenation of cyclohexene and benzene over $\mathrm{Ni}-\mathrm{WS}_{2} / \mathrm{Al}_{2} \mathrm{O}_{3}$ is to create more $\mathrm{W}^{3+}$ sites [17]. He assumed that the catalytically active site is an exposed $\mathrm{W}^{3+}$ cation, because he observed a linear relationship between the hydrogenation activity and the intensity of an ESR signal ascribed to $W^{3+}$ [99]. Konings et al. [100-102] found a similar relationship between the HDS activity of thiophene and the intensity of an ESR signal in $\mathrm{Co}-\mathrm{MoS}_{2} / \mathrm{Al}_{2} \mathrm{O}_{3}$ catalysts. They assigned this signal to $\mathrm{Mo}^{3+}$ ions, while others $[103,104]$ have assigned it to Mo cations in higher oxidation states. In analogy with the intercalation of alkali metals between the layers of $\mathrm{MoS}_{2}$, Voorhoeve proposed that nickel or cobalt atoms can be intercalated between alternating $\mathrm{MoS}_{2}$ layers. However, other studies demonstrated that intercalation of Co and $\mathrm{Ni}$ and the formation of ternary sulfides is impossible [27-29].

Farragher and Cossee therefore suggested that the cobalt is located at the edges of the $\mathrm{MoS}_{2}$ crystals, in between alternate layers [26]. This model is often referred to as the decoration, or pseudointercalation model (see Fig. 6). To explain the role of the promoter ions, Farragher and Cossee assumed that they induced a surface reconstruction of the edges of the $\mathrm{MoS}_{2}$ layers. Such a surface reconstruction leads to more exposed Mo cations and thus to an enhanced activity. Assuming that the normal $\mathrm{MoS}_{2}$ surface is relaxed [32], so that many Mo cations are covered by sulfur ions, promoter ions in pseudointercalation positions may lead to a substantial enhancement in activity. It is questionable, however, that a 10 to 30 -fold increase in 


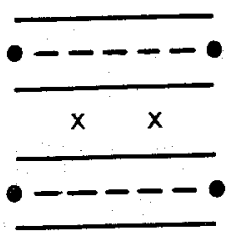

Voorhoeve

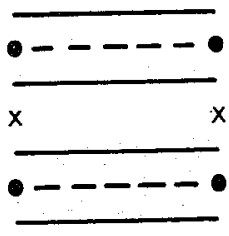

Farragher

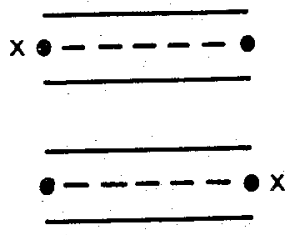

Topsøe

- active site

$x$ promoter ion

FIG. 6. Schematic picture of the location of the Co promoter ions in $\mathrm{MoS}_{2}$ according to the models of Voorhoeve, Farragher, and Topsøe.

exposed Mo cations can be achieved. Also, the proposed surface reconstruction places the promoter ions in octahedral sites, in disagreement with a Co-NMR study of Ledoux et al. [37], who found the cobalt ions to be located in tetrahedral sites.

As indicated in Section II.B, from IR studies of NO molecules adsorbed on the $\mathrm{Co}-\mathrm{MoS}_{2} / \mathrm{Al}_{2} \mathrm{O}_{3}$ catalyst surface Topsøe and Topsøe concluded that the promoter ions are not located between $\mathrm{MoS}_{2}$ layers, but in the $\mathrm{MoS}_{2}$ layers, in the plane of the Mo cations (see Fig. 6) [36]. In that case the Mo ions should become covered by the promoter ions; if only Mo ions are active, the activity should decrease by the addition of Coi or $\mathrm{Ni}$ ions. Obviously, if the location of the promotor ions is as described by Topsøe and Topsøe, the textural promoter model is incorrect. Shuxian et al. have reported, however, that NO dissociates on the $\mathrm{MoS}_{2}$ surface above $130 \mathrm{~K}$, and that the resulting oxygen atoms lead to surface oxidation above $200 \mathrm{~K}$ (105]. They concluded that NO adsorbed on supported Mo catalysts in the sulfided state may not reflect the nature of the coordination sites on fully sulfided catalysts, but rather may be characteristic of a partially reoxidized material. Further work is needed to clarify the questions by the work of Shuxian et al. and to see if the conclusions about the location of the promoter ions drawn from the IR adsorption study [36] need reinterpretation.

The influence of the promoter ion on the surface of the $\mathrm{MoS}_{2}$ or $\mathrm{WS}_{2}$ crystallites was shown by Farragher and Cossee. Their electron 
microscopy results of unsupported $\mathrm{WS}_{2}$ promoted by Ni showed that the shape of the $\mathrm{WS}_{2}$ crystal edges changed and that nickel induced a random faceting of the $\mathrm{WS}_{2}$ edge surface [26]. Furthermore, Delmon et al. observed changes in the X-ray diffraction patterns of $\mathrm{MoS}_{2}$ after addition of small amounts of $\mathrm{Co}$, indicating a decrease in the $\mathrm{c} / \mathrm{a}$ ratio of the crystal axis perpendicular to the basal plane of $\mathrm{MoS}_{2}$ and the axis in that plane [106]. Furthermore, Candia et al. [107] observed a decrease in the $\mathrm{MoS}_{2}$ crystal size perpendicular to the basal plane at $\mathrm{Co} / \mathrm{Mo}=0.25$ in catalysts prepared by the comaceration method (in which an aqueous solution of $\left(\mathrm{NH}_{4}\right)_{2} \mathrm{~S}$ is added to a mixture of $\mathrm{MoO}_{3}$ and $\mathrm{Co}_{3} \mathrm{O}_{4}$ ), as well as in catalysts prepared by the homogeneous sulfide precipitation method (in which a hot solution of a mixture of $\mathrm{Co}\left(\mathrm{NO}_{3}\right)_{2}$ and $\left(\mathrm{NH}_{4}\right)_{6} \mathrm{Mo}_{7} \mathrm{O}_{24}$ is poured into a hot solution of $\left(\mathrm{NH}_{4}\right)_{2} \mathrm{~S}$ under vigorous stirring). These studies confirm that the promoter is located at the surface, but do not constitute proof for the textural role of the promoter. A few years ago Vrinat and de Mourgues proposed once again that the role of the promoter is to influence the dispersion and morphology of the $\mathrm{MoS}_{2}$ crystallites [108]. They observed that the activation energies for the HDS of dibenzothiophene over unsupported $\mathrm{MoS}_{2}$ and $\mathrm{Co}_{9} \mathrm{~S}_{8}$, as well as over $\mathrm{Co}-\mathrm{MoS}_{2}$ prepared via the comaceration procedure, are equal. This was taken to indicate that the same Mo sites are active in $\mathrm{Co}-\mathrm{MoS}_{2}$ as in $\mathrm{MoS}_{2}$. However, it is known that separate crystallites of $\mathrm{MoS}_{2}$ and $\mathrm{Co}_{9} \mathrm{~S}_{8}$ are formed in the comaceration method $[107,109,110]$, and since apparently $\mathrm{Co}_{9} \mathrm{~S}_{8}$ and $\mathrm{MoS}_{2}$ have the same activation energy, actually no conclusion at all can be drawn from these results. Furthermore, Pratt et al. observed different activation energies in the HDS of thiophene over unsupported $\mathrm{MoS}_{2}, \mathrm{Ni}_{3} \mathrm{~S}_{2}$, and $\mathrm{Ni}-\mathrm{MoS}_{2}$ prepared via comaceration [111].

At present, the location of the promoter ion as described by Topsøe and Topsøe is widely accepted. In this case the role of the promoter cannot be textural. Confirmation of this conclusion would be welcome, via an independent study of the location of the promoter, as well as a study of the activation energies of an unpromoted catalyst and a promoted catalyst with all or more of the promoter ions in the $\mathrm{Co}-\mathrm{Mo}-\mathrm{S}$ phase.

\section{B. Co Role in Hydrogen Spillover}

A completely different model has been proposed by Delmon [112]. Based on the knowledge that in the comaceration procedure, separate crystallites of $\mathrm{Co}_{9} \mathrm{~S}_{8}$ and $\mathrm{MoS}_{2}$ are formed, and that such a mixture also shows a promotion effect, he proposed that the role of the 
promoter sulfide is to provide hydrogen atoms to $\mathrm{MoS}_{2}$. These spilledover $\mathrm{H}$ atoms would create reduced centers on the $\mathrm{MoS}_{2}$ surface, which would be the catalytically active sites. The $\mathrm{Co}_{9} \mathrm{~S}_{8}$ then has a "remote control" over the $\mathrm{MoS}_{2}$ surface. In line with this proposal, Eijsbouts et al. observed in a study of the hydrodenitrogenation of quinoline that $\mathrm{MoS}_{2}$ has relatively poor hydrogenation properties [113]. On the other hand, $\operatorname{Co}_{9} \mathrm{~S}_{8}$ also had poor hydrogenation properties and would not be able to increase the overall hydrogenation rate of a mixture of these metal sulfides. A very convincing argument against the remote control model came from the combined Mössbauer and activity studies of Wivel et al. [21]. They demonstrated that even when the presence of minor amounts of $\mathrm{Co}_{9} \mathrm{~S}_{8}$ could be excluded, the catalytic activity was increased by a factor of 30 by the addition of cobalt $(\mathrm{Co} / \mathrm{Mo}<0.4)$. Also, when at high cobalt loading $\mathrm{Co}_{9} \mathrm{~S}_{8}$ became the dominant cobalt phase, the catalytic activity actually decreased. Therefore Wivel et al. attributed the promotion effect to cobalt present in the $\mathrm{Co}-\mathrm{Mo}-\mathrm{S}$ phase, with cobalt ions located at the $\mathrm{MoS}_{2}$ surface.

\section{Co Role as Bonding Modifier of the Mo Site}

The idea that the promoter ion influences a neighboring Mo site and in fact creates a much more active site has been proposed by Chianelli et al. $[114,115]$. Originally they proposed that a mixed CoMo site with a shared sulfur vacancy was responsible for the improved catalytic activity, and they argued that the average heat of formation of $\mathrm{MoS}_{2}$ and $\mathrm{Co}_{9} \mathrm{~S}_{8}$ would be perfect for an optimum reaction rate. The average heat of formation would be intermediate between a too strong and a too weak heat of formation, and as a result the mixed CoMo site would have an activity near the maximum of the Balandin volcano curve [114]. In their theoretical calculations on the promoter effect, however, Harris and Chianelli have rejected this mixed site model, because they calculated that the $M-S$ bond strength did not change significantly upon introduction of a promoter ion [115]. Instead, they proposed that the electron density at the Mo sites is increased by $\mathrm{Co}$ and Ni promoter ions, and that the modified, reduced Mo sites have a higher activity. Their conclusions are based on SCF-X $\alpha$ scattered wave calculations of $\left(\mathrm{MS}_{6}\right)^{n-}$ and $\left(\mathrm{S}_{3} \mathrm{MS}_{3} \mathrm{MoS}_{3}\right)^{m-}$ complexes $[115,116]$. They assumed that such complexes are representative of the environment of the metal cations at the catalyst surface. In their calculations they took all cations to be octahedrally surrounded by sulfur anions, and they gave the cations 
the same oxidation state as they have in the bulk of the most stable metal sulfides. For instance, the Mo cations were taken to be $\mathrm{Mo}^{4+}$ ions, and the $\mathrm{Co}$ and $\mathrm{Ni}$ cations to be $\mathrm{M}^{2+}$ ions. Without much explanation they furthermore assumed that the catalytic activity is proportional to the product of the $\mathrm{M}-\mathrm{S}$ bond strength and the number of electrons in the highest occupied molecular orbital (HOMO).

Several questions may be raised about all these assumptions. Firstly, since they concentrated their calculations on the bond strength of the $\mathrm{M}-\mathrm{S}$ bond in a fully coordinated complex, this would suggest that the $\mathrm{M}-\mathrm{S}$ bond breaking (the second step in the reaction mechanism, subsequent to the initial desulfurization of the sulfur-containing molecule) is the rate-determining step. However, this assumption has not been experimentally verified yet. Secondly, their choice of the oxidation state of the surface cation to be equal to that of the bulk cation is debatable as well. As indicated by Goodenough [48], surface cations may have a lower charge than bulk cations. Also, as indicated in Section IV.A, some authors have observed a linear relationship between catalytic activity and the amount of $\mathrm{Mo}^{3+}$ or $\mathrm{W}^{3+}$ surface cations [99-102]. Furthermore, $\mathrm{Zr}^{4+}$ and $\mathrm{Hf}^{4+}$ ions have no electrons in $d$ orbitals, and as a consequence the Harris-Chianelli theory predicts $\mathrm{TiS}_{2}$ and $\mathrm{ZrS}_{2}$ to have zero activity, whereas in unsupported form they had activities for the HDS of dibenzothiophene comparable to $\mathrm{VS}_{2}, \mathrm{NbS}_{2}$, and $\mathrm{TaS}_{2}$ with $d^{1}$ electronic structures [42]. On the other hand, when supported on carbon $\mathrm{TiS}_{2}, \mathrm{ZrS}_{2}$, and $\mathrm{HfS}_{2}$ had lower activities for the HDS of thiophene than $\mathrm{VS}_{2}, \mathrm{NbS}_{2}$, and $\mathrm{TaS}_{2}$ [44]. Therefore, it would be of interest to repeat the calculations on $\left(\mathrm{MS}_{6}\right)^{n-}$ and $\left(\mathrm{S}_{3} \mathrm{MS}_{3} \mathrm{MoS}_{3}\right)^{m-}$ complexes with $\mathrm{M}$ in the bulk minus one oxidation state in the former complex, and $\mathrm{Mo}$ in the $\mathrm{Mo}^{3+}$ state in the latter complex.

From their calculations on $\left(\mathrm{MS}_{6}\right)^{n-}$ complexes, Harris and Chianelli concluded that differences in catalytic activities between different transition metal sulfides are due to electronic factors, such as electron occupancy of the HOMO and covalency of the $d$ orbitals [116]. The calculations on $\left(\mathrm{S}_{3} \mathrm{MS}_{3} \mathrm{MoS}_{3}\right)^{m-}$ complexes, in which $M$ was varied from $\mathrm{V}$ to $\mathrm{Zn}$, indicated that the promotion effect is related to the donation of electrons from promoter ion to $\mathrm{Mo}^{4+}$.

The energy levels of the $\mathrm{e}_{g}$ HOMOs of the Co and Ni complexes are especially well suited for electron donation to the $t_{2 g}$ HOMO of $\mathrm{Mo}^{4+}$ [115]. This electron-donation model of Harris and Chianelli is very similar to the qualitative models proposed earlier by Voorhoeve [17], De Beer and Schuit [6], and Gates et al. [40]. Electron donation leads to weakening of the Mo-S bond in all these models. 
Electron transfer was also considered by Wentrcek and Wise [117]. These authors studied the electric conductivity of a cobalt-doped $\mathrm{MoS}_{2}$ single crystal and observed that an increase in hole carrier density increased the catalytic activity. This observation seems to contradict all other models, which assume a higher activity with higher electron density. On the other hand, the data of Wentrcek and Wise seem to be internally conflicting, because a longer prereduction of the $\mathrm{MoS}_{2}$, crystal gave a higher HDS conversion (suggesting more vacancies) but a lower electron conductivity (suggesting less free electrons). This is counter to the expectation based on the equation $\mathrm{H}_{2}+\mathrm{S}^{2-} \leftrightharpoons \mathrm{H}_{2} \mathrm{~S}+2 \mathrm{e}+\square$, where $\square$ represents an anion vacancy.

\section{Determination of the Number of Active Sites}

A way to determine if the promoter ion just creates more sulfur vacancies, or if it changes the nature of the active site, would be to determine the number of active sites. Tauster et al. reported that the $\mathrm{O}_{2}$ uptake of unsupported $\mathrm{MoS}_{2}$ samples, measured by pulsed, dynamic $\mathrm{O}_{2}$ chemisorption, varied linearly with HDS activity [118], while Bachelier et al. observed a similar effect for sulfided $\mathrm{Ni} / \mathrm{Al}_{2} \mathrm{O}_{3}$ catalysts [119]. These findings aroused a great deal of interest, mainly focused on the establishment of a routine technique which could replace time-consuming activity testing. Only a few $\mathrm{O}_{2}$ chemisorption studies were devoted to learning more about the catalyst surface. Thus, Zmierczak et al. studied the $\mathrm{O}_{2}$ chemisorption, thiophene HDS activity, and hexene hydrogenation activity of sulfided Mo and CoMo catalysts on various supports [120)]. Their most important conclusion was that $\mathrm{O}_{2}$ chemisorption is corrosive. A stable $\mathrm{O}_{2}$ adsorption was only obtained at $-78^{\circ} \mathrm{C}$. At higher temperatures a continued $\mathrm{O}_{2}$ consumption indicated slow oxidation of the sulfided Mo and CoMo catalysts. Recent TEM studies support these results. Chianelli and Daage showed that short exposure of unsupported $\mathrm{MoS}_{2}$ to oxygen during dynamic $\mathrm{O}_{2}$ chemisorption resulted in substantial oxidation of the crystals [121]. A ring of oxidized material, about $50 \AA$ thick, was observed around the edges of the crystals. The fact that this oxidation was topotactic explains why a linear relationship is observed between $\mathrm{O}_{2}$ chemisorption and HDS activity for a certain class of catalysts (e.g., $\mathrm{MoS}_{2}$ ), but another relationship is observed for another class of catalysts (e.g., promoted $\mathrm{MoS}_{2}$ ). Both $\mathrm{O}_{2}$ chemisorption and HDS activity are linearly dependent on the crystal edge surface area, and therefore there is also a linear relationship between chemisorption and activity. However, this relationship will depend on factors such as $\mathrm{O}_{2}$ 
pressure, temperature and exposure time during chemisorption, and on the type of crystal surface (e.g., promoted or unpromoted). Since $\mathrm{O}_{2}$ chemisorption reflects the general state of dispersion of the (un)promoted catalyst rather than specific sites, at present $\mathrm{O}_{2}$ chemisorption cannot be used for the quantitative determination of active sites [120]. Expressions of definite opinions about the function of the promoter, based on $\mathrm{O}_{2}$ chemisorption [122], should therefore not be taken without reserve.

The use of the less aggressive $\mathrm{CO}$ as an adsorbent for the determination of the active surface area of a sulfide catalyst has been investigated by Bachelier et al. $[123,124]$. They observed that $\mathrm{CO}$ binds somewhat stronger to $\mathrm{MoS}_{2}$ than to $\mathrm{Al}_{2} \mathrm{O}_{3}$ and proposed the use of $\mathrm{CO}$ adsorption at $0^{\circ} \mathrm{C}$ as a measure for the sulfide surface area. At this temperature $\mathrm{CO}$ appears to adsorb preferentially on $\mathrm{MoS}_{2}$. The extent of coverage at this temperature remains an open question, however. More investigations are required before this method can be accepted as a reliable method for a quantitative determination of the active surface area of a sulfide catalyst. In this respect, studies of different metal sulfides would also be of interest. Also, NO has been tried as a selective adsorbent on the active surface of metal sulfides $[36,105,125]$. The infrared and adsorption results of Topsøe and Topsøe [36] have already been discussed in Sections II.B and IV.A in relation to the location of the promoter ions. These results demonstrated that for $\mathrm{NO}$, as well as for $\mathrm{O}_{2}$, there is a good correlation between chemisorption and HDS activity of $\mathrm{MoS}_{2} / \mathrm{Al}_{2} \mathrm{O}_{3}$ catalysts, but not for promoted catalysts. Contradictory information comes from publications by Shuxian et al. [105] and Miciukiewicz et al. [125]. From XPS studies of the adsorption of $\mathrm{O}_{2}$ and $\mathrm{NO}$ on polycrystalline $\mathrm{MoS}_{2}$, Shuxian et al. conclude that NO adsorbs dissociatively above $130 \mathrm{~K}$ and that the resulting oxygen atoms lead to surface oxidation above $200 \mathrm{~K}$. They therefore suggest that one should be careful in interpreting IR spectra of adsorbed NO. On the other hand, Miciukiewicz et al. showed that NO adsorbed as well on the $\mathrm{MoS}_{2}$ as on the support in sulfided $\mathrm{Mo} / \mathrm{Al}_{2} \mathrm{O}_{3}$ catalysts, and that both adsorptions decreased with temperature [125]. A rough calculation based on their data indicates that the heat of adsorption would be only about $1 \mathrm{kcal}$. It is difficult to see how such a weak bonding could lead to (corrosive) chemisorption. Further work on NO adsorption is needed to clarify these questions.

We conclude that the problem of how to determine the active surface area of an HDS catalyst remains to be solved. Attempts will certainly continue, because this problem is important and hampers 
progress in hydrotreating catalysis. A method to measure the active catalytic surface area would be of importance not only as a standard test, but also for calculating turnover frequencies and comparing intrinsic activities of catalysts. It would also shed light on the function of the HDS promoter.

\section{E. Co as Producer of a New Catalytic Site}

A completely different model was proposed by De Beer, Duchet, and Prins $[49,126]$. They noted that the activities of cobalt and nickel sulfide supported on carbon for thiophene HDS were higher than that of $\mathrm{MoS}_{2} / \mathrm{C}$ and suggested that cobalt and nickel sulfide might act as the catalyst instead of the promoter. Sulfided cobalt or nickel on $\mathrm{Al}_{2} \mathrm{O}_{3}$ catalysts have a low HDS activity, and therefore $\mathrm{Co}$ and $\mathrm{Ni}$ were never considered to be able to act as catalysts in sulfided CoMo and NiMo systems. But it is clear now that during usual catalyst preparation, cobalt and nickel ions interact strongly with $\mathrm{Al}_{2} \mathrm{O}_{3}$. So, either part of these metal ions is not sulfided at all and thus does not contribute to HDS activity, or the application of more severe sulfidation conditions lowers the dispersion and activity [119]. Consequently, a higher activity for a CoMo or NiMo catalyst is obtained when in the preparation procedure the Mo impregnation is applied before the Co impregnation, counteracting the strong interaction between cobalt and nickel ions and $\mathrm{Al}_{2} \mathrm{O}_{3}$. The carbon- supported cobalt and nickel sulfide catalysts demonstrate that when these catalysts are prepared with a high dispersion, they indeed have a high activity.

That cobalt and nickel sulfide are at least as active, or may be more active than $\mathrm{MoS}_{2}$ is not an isolated case. Pecoraro and Chianelli [42], Vissers et al. [43], and Ledoux et al. [44] have demonstrated that many transition metal sulfides have a higher HDS activity than $\mathrm{MoS}_{2}$ or $\mathrm{WS}_{2}$. Apparently a high HDS activity is not inherent to layer-lattice metal sulfides such as $\mathrm{MoS}_{2}$ and $\mathrm{WS}_{2}$, because most transition metal sulfides have a different crystal structure. For the $4 \mathrm{~d}$ and $5 \mathrm{~d}$ metal sulfides, a Balandin volcano-type activity behavior was observed, with maxima in the HDS of dibenzothiophene for unsupported $\mathrm{RuS}_{2}$ and $\mathrm{OsS}_{2}$ [42], and maxima in the HDS of thiophene for rhodium and iridium sulfide supported on carbon $[43,44]$.

Burch and Collins found that nickel sulfide was much more active when supported on $\mathrm{SiO}_{2}$ than on $\mathrm{Al}_{2} \mathrm{O}_{3}$ and suggested that this may be caused by a dependence of the nickel sulfide morphology on the support [127]. In the $\mathrm{Ni}_{3} \mathrm{~S}_{2}$ structure the metal ions are located at pseudotetrahedral sites, whereas in NiS with the NiAs structure, each 
nickel ion is at an octahedral site. Since one may expect that the nickel ions will be more active when more exposed (as in a tetrahedral site, compared with an octahedral site), the thermodynamically more stable $\mathrm{Ni}_{3} \mathrm{~S}_{2}$ would be the more active phase. Sulfided $\mathrm{Ni} / \mathrm{SiO}_{2}$ has an activity comparable to that of unsupported $\mathrm{Ni}_{3} \mathrm{~S}_{2}$, while sulfided $\mathrm{Ni} / \mathrm{C}$ has an activity which is about twice as high, and sulfided $\mathrm{Ni} / \mathrm{Al}_{2} \mathrm{O}_{3}$ has an activity which is about nine times lower than that of sulfided $\mathrm{Ni} / \mathrm{SiO}_{2}$ [127]. Burch and Collins therefore proposed that, not the carbon support, but the $\mathrm{Al}_{2} \mathrm{O}_{3}$ support is special, and that the low activity of $\mathrm{Al}_{2} \mathrm{O}_{3}$-supported nickel sulfide arises because on this support nickel is not present as $\mathrm{Ni}_{3} \mathrm{~S}_{2}$, but as NiS.

In their solid-state ${ }^{59} \mathrm{Co}$ NMR study of $\mathrm{SiO}_{2}$ and carbon-supported cobalt sulfide, Ledoux et al. found that the ${ }^{59} \mathrm{Co}$ NMR spectra gradually changed when lowering the cobalt loading [37]. At high loading the spectra consisted of a contribution due to $\mathrm{Co}$ in tetrahedral sites and one due to $\mathrm{Co}$ in octahedral sites. Their intensity ratio of $8: 1$ revealed that $\mathrm{Co}_{9} \mathrm{~S}_{8}$ was the cobalt phase present. At low loadings of Co on $\mathrm{SiO}_{2}$ a new single line appeared, with a short relaxation time. The corresponding site most probably is a distorted octahedral site. Especially apparent for the cobalt sulfide on carbon samples was a broad underlying contribution to the ${ }^{59} \mathrm{Co}$ spectra, attributed to cobalt sites with distorted tetrahedral symmetry. These new tetrahedral sites were held responsible for the high HDS activity of cobalt sulfide on carbon and on $\mathrm{SiO}_{2}$. Ledoux et al. also pointed out that according to the Harris-Chianelli theory [115], a cobalt ion in a tetrahedral site should be more active than one in an octahedral site. For a $\mathrm{Co}^{2+}$ ion in a tetrahedral site, the HOMO is a $t_{2}$ orbital and holds three electrons, while in an octahedral site the HOMO is the $\mathrm{e}_{g}$ orbital and, depending on the spin situation, holds two or one electrons. Thus, Ledoux et al. [37] agree with de Beer et al. $[49,126]$ that cobalt sulfide itself is very active, and like Burch and Collins [127] they ascribe this to modification of the sites.

The activity of their CoMo catalysts was broadly explained by Ledoux et al. in terms of additivity of the $\mathrm{MoS}_{2}$ and cobalt sulfide activities [37]. Several assumptions were made, however. In fact they actually reversed the quantitative analysis by assuming that the Mo and Co sites have equal activity and calculated the $\mathrm{MoS}_{2}$ and cobalt sulfide dispersions from the activities. Since the resulting dispersions seemed reasonable, Ledoux et al. claimed that there was no reason to look for new or improved sites in CoMo catalysts. Although minor changes in the assumptions may not leave much to desire in a qualitative sense, they do in a quantitative sense. The outstanding problem 
here is, again, the inability to determine the dispersion of metal sulfides.

Recently Vissers, de Beer, and Prins made an attempt to solve this problem by measuring the thiophene HDS activities of series of sulfided $\mathrm{Mo} / \mathrm{C}$ and $\mathrm{Co} / \mathrm{C}$ catalysts with varying metal loading. They noted that at equal atomic loading the Co catalysts were about two to three times more active than the Mo catalysts [128]. XPS intensity measurements indicated, however, that $\mathrm{Co}$ was much less well dispersed than Mo. The activity per mole of metal present of both metal sulfides increased with decreasing metal loading, but much more strongly for cobalt sulfide. By extrapolating these activities to zero metal loading, Vissers et al. obtained a sevenfold higher activity for cobalt sulfide than for $\mathrm{MoS}_{2}$. Since the very best dispersion is expected at very low loading, the ratio of 7 for the relative activity of Co to Mo seems the best value to use whenever all or most of the cobalt is exposed. In sulfided CoMo catalysts with $\mathrm{Co} / \mathrm{Mo}$ ratios below 1 , the cobalt ions are all in the $\mathrm{CO}-\mathrm{Mo}-\mathrm{S}$ phase and well dispersed [2022].

Vissers et al. explained the activity of a sulfided $\mathrm{CoMo} / \mathrm{C}$ catalyst completely by the very high activity of the cobalt sites. Also, the observed ratio of the rates of hydrogenation and HDS for the $\mathrm{CoMo} / \mathrm{C}$ catalyst was close to that of sulfided $\mathrm{Co} / \mathrm{C}$, and substantially different from that of $\mathrm{MoS}_{2} / \mathrm{C}$. Accordingly $\mathrm{MoS}_{2}$ should be regarded as a support for the cobalt sulfide phase, enabling the cobalt sulfide to be optimally dispersed and preventing its disappearance into the $\mathrm{Al}_{2} \mathrm{O}_{3}$ carrier. Two assumptions in this cobalt site theory need verification. The first is that it was implicitly assumed that a cobalt site in sulfided $\mathrm{Co} / \mathrm{C}$ has the same activity as a cobalt site in sulfided $\mathrm{CoMo} / \mathrm{S}$. This does not have to be the case, however, as indicated by the morphology arguments of Burch and Collins [127]. The second assumption is that the method of extrapolating the quasi-turnover frequencies to zero metal loading not only leads to very high percentages of exposed cations for both Mo and $\mathrm{Co}$, but actually to equal percentages. Experimental verification of the latter assumption must await the development of a reliable method to measure the percentage exposed.

In summary, although quite some experimental work has been performed with the aim of clarifying the role of the cobalt promoter in HDS catalysts, most models proposed can explain the experimental results. Only the remote control model cannot explain the activity and Mössbauer results of Topsøe and Topsøe. But the textural model, the modified Mo site model, and the new catalytic Co site model should all 
still be taken into full consideration. Future work should aim at designing experiments to differentiate between these models. One way to do this, which would also be of great value to other areas of HDS catalysis, would be to devise a method to measure the percentage of exposed molybdenum and cobalt cations.

\section{CONCLUSIONS AND DIRECTIONS FOR THE FUTURE}

In this review we have addressed the question of structure and function of HDS catalyst and promoter. In succession, we discussed the chemical identity of molybdenum and cobalt (sulfidic versus oxidic), the geometric and electronic structure of the Mo and Co ions at the surface of the catalyst, and the models which have been proposed to explain their catalytic activity. It is obvious from the material reviewed that a wealth of new information has become available in recent years, and that new avenues have been opened by research in organometallic chemistry and surface science. It is to be expected that in combination with the classic solid-state chemistry approach, these new influxes will generate a breakthrough in our understanding of HDS catalysis.

From the material discussed it is clear that the key question of how a HDS catalyst functions is completely open again. For a long time it was thought that the solid-state model with $\sigma$-bonding of thiophene into a sulfur vacancy around an Mo ion was the final word in explaining the function of the Mo catalyst proper. But organometallic chemistry and surface science have shown that there are alternative possibilities, such as reactions in the second coordination sphere of Mo, for instance, via persulfide ligand formation, or of $\pi$-bonding of thiophene to Mo.

Even more open is the question of the function of a $\mathrm{Co}$ or $\mathrm{Ni}$ promoter in HDS catalysis. Although the remote control model can now be disregarded, the other three models should all still be taken seriously. As explained in Sections III and IV, what is presently hampering progress in HDS catalysis is the lack of knowledge of the (active) surface area of these catalysts. Although the $\mathrm{O}_{2}$ chemisorption method has proved to be of value for ranking of catalysts, it is a corrosive method and therefore of no use for a fundamental understanding of the surface of these catalysts. Other methods should be explored, but it will take time before a reliable method is found and generally accepted. 
Conversely, the question of the location of the promoter ions has to a great extent been solved by the Mössbauer studies of the Topsøe group. It is now generally agreed that the cobalt (or nickel) ions which are responsible for the large increase in catalytic activity, are located around the edges of the $\mathrm{MoS}_{2}$ crystallites. Questions remain about their exact location-either in the plane of the Mo ions or in between successive $\mathrm{MoS}_{2}$ sandwich layers-and their structure-whether in tetrahedral, octahedral, or other kinds of sites.

It is comforting to see that respected research groups from other fields than traditional catalysis, like organometallic chemistry and surface science, have become interested in the scientific problems posed by HDS catalysts and catalysis. New ideas from different areas are very welcome in the field, because it is not an easy field and there are still many questions to be solved. For instance, in addition to the cobalt or nickel promoter, many other promoters $(\mathrm{P}, \mathrm{F}, \mathrm{Cl}, \mathrm{B}$, and others) have been described in patent literature, some of which are indeed used in industrial recipes for catalyst manufacture. Only when the role of Mo and Co is understood will progress be made with the role of these other promoters. Finally, the related subjects of hydrodenitrogenation, deoxygenation, and demetallization are at least as complicated as-and probably even much more complicated than-hydrodesulfurization. All these hydrotreating reactions are of great importance for cleaning up oil and oil products, and for preventing damage to the environment.

\section{REFERENCES}

[1] C. N. Satterfield and S. H. Yang, Ind. Eng. Chem. Proc. Des. Dev., 23, 11 (1984).

[2] H. Schulz, M. Schon, and N. M. Rahman, Stud. Surf. Sci. Catal., 27, 201 (1986).

[3] E. Furimsky, Catal. Rev.-Sci. Eng., 25, 421 (1983).

[4] C. L. Lee and D. F. Ollis, J. Catal., 87, 325, 332 (1984).

[5] R. A. Ware and J. Wei, J. Catal., 93, 100, 122, 135 (1985).

[6] V. H. J. de Beer and G. C. A. Schuit, in Preparation of Catalysts (B. Delmon, P. A. Jacobs, and G. Poncelet, eds.), Elsevier, Amsterdam, 1976, p. 343.

[7] F. E. Massoth, Adv. Catal., 27, 265 (1978).

[8] P. Grange, Catal. Rev.-Sci. Eng., 21, 135 (1980).

[9] P. Ratnasamy and S. Sivasanker, Catal. Rev.-Sci. Eng., 22, 401 (1980).

[10] B. S. Clausen, H. Topsøe, R. Candia, J. Villadsen, B. Lengeler, J. Als-Nielsen, and F. Christensen, J. Phys. Chem., 85, 3868 (1981). 
[11] T. G. Parham and R. P. Merrill, J. Catal., 85, 295 (1984).

[12] N.-S. Chiu, S. H. Bauer, and M. F. L. Johnson, J. Catal., 89, 226 (1984); ibid., 98, 32 (1986).

[13] P. Arnoldy, J. A. M. van den Heijkant, G. D. de Bok, and J. A. Moulijn, J. Catal., 92, 35 (1985).

[14] B. Scheffer, J. C. M. de Jonge, P. Arnoldy, and J. A. Moulijn, Bull. Soc. Chim. Belg., 93, 751 (1984).

[15] H. Topsøe and B. S. Clausen, Catal. Rev.-Sci. Eng., 26, 395 (1984).

[16] T. F. Hayden and J. A. Dumesic, J. Catal., 103, 366 (1987).

[17] R. J. H. Voorhoeve and J. C. M. Stuiver, J. Catal., 23, 228, 243 (1971).

[18] M. Salmeron, G. A. Somorjai, A. Wold, R. R. Chianelli, and K. S. Liang, Chem. Phys. Lett., 90, 105 (1982).

[19] M. H. Farias, A. J. Gellman, G. A. Somorjai, R. R. Chianelli, and K. S. Liang, Surf. Sci., 140, 181 (1984).

[20] H. Topsøe, B. S. Clausen, R. Candia, C. Wivel, and S. Mørup, J. Catal., 68, 433 (1981).

[21] C. Wivel, R. Candia, B. S. Clausen, S. Mørup, and H. Topsøe, J. Catal., 68, 453 (1981).

[22] C. Wivel, B. S. Clausen, R. Candia, S. Mørup, and H. Topsoe, J. Catal., 87, 497 (1984).

[23] F. Delannay, E. Haeussler, and B. Delmon, J. Catal., 66, 469 (1980).

[24] S. Kasztelan, J. Grimblot, and J. P. Bonnelle, J. Phys. Chem., 91, 1503 (1987).

[25] H. Topsøe and B. S. Clausen, Appl. Catal., 25, 273 (1986).

[26] A. L. Farragher and P. Cossee, in Proc. 5th Int. Congress Catalysis, Palm Beach, 1972, North-Holland, Amsterdam, 1973, p. 1301.

[27] J. M. van den Berg, Inorg. Chim. Acta, 2, 216 (1968).

[28] K. Anzenhofer and J. J. de Boer, Acta Cryst., B25, 1419 (1969).

[29] G. Hagenbach, Ph. Courty, and B. Delmon, J. Catal., 23, 295 (1971).

[30] J. M. van den Berg and P. Cossee, Inorg. Chim. Acta, 2, 143 (1968).

[31] K. Anzenhofer, J. M. van den Berg, P. Cossee, and J. N. Helle, J. Phys. Chem. Solids, 31, 1057 (1970).

[32] A. L. Farragher, Adv. Colloid Interface Sci., 11, 3 (1979).

[33] R. R. Chianelli, A. F. Ruppert, S. K. Behal, B. H. Kear, A. Wold, and R. Kershaw, J. Catal., 92, 56 (1985).

[34] B. S. Clausen, B. Lengeler, R. Candia, J. Als-Nielsen, and H. Topsøe, Bull. Soc. Chim. Belg., 90, 1249 (1981).

[35] S. H. Bauer, N.-S. Chiu, and M. F. L. Johnson, J. Phys. Chem., 90, 4888 (1986).

[36] N.-Y. Topsøe and H. Topsøe, J. Catal., 84, 386 (1983).

[37] M. J. Ledoux, O. Michaux, G. Agostini, and P. Panissod, J. Catal., 96, 189 (1985).

[38] S. Kasztelan, H. Toulhoat, J. Grimblot, and J. P. Bonnelle, Appl. Catal., 13, 127 (1984).

[39] E. J. Arlman, J. Catal., 3, 89 (1964). 
[40] B. G. Gates, J. R. Katzer, and G. C. A. Schuit, in Chemistry of Catalytic Processes, McGraw-Hill, New York, 1979, p. 423.

[41] G. C. A. Schuit, Int. J. Quantum Chem., 12, 43 (1977).

[42] T. A. Pecoraro and R. R. Chianelli, J. Catal., 67, 430 (1981).

[43] J. P. R. Vissers, C. K. Groot, E. M. van Oers, V. H. J. de Beer, and R. Prins, Bull. Soc. Chim. Belg., 93, 813 (1984).

[44] M. J. Ledoux, O. Michaux, G. Agostini, and P. Panissod, J. Catal., 102, 275 (1986).

[45] J. M. J. G. Lipsch and G. C. A. Schuit, J. Catal., 15, 179 (1969).

[46] H. Kwart, G. C. A. Schuit, and B. C. Gates, J. Catal., 61, 128 (1980).

[47] P. H. M. Budzelaar, to be published.

[48] J. B. Goodenough, in Fourth Int. Conf. on the Chemistry and Uses of Molybdenum (H. F. Barry and P. C. H. Mitchell, Eds.), Climax Molybdenum Corp., Golden, U.S.A., 1982, p. 1.

[49] J. C. Duchet, E. M. van Oers, V. H. J. de Beer, and R. Prins, J. Catal., 80, 386 (1983).

[50] P. R. Sarode, G. Sankar, A. Srinivasan, S. Vasudevan, C. N. R. Rao, and J. M. Thomas, Angew. Chem., 96, 288 (1984).

[51] E. L. Muetterties and J. Stein, Chem. Rev., 79, 479 (1979).

[52] D. A. Lesch, J. W. Richardson, Jr., R. A. Jacobson, and R. J. Angelici, J. Am. Chem. Soc., 106, 2901 (1984).

[53] J. D. Goodrich, P. N. Nickias, and J. P. Selegue, Inorg. Chem., 26, 3424 (1987).

[54] R. A. Sanchez-Delgado, R. L. Marquez-Silva, J. Puga, A. Tiripicchio, and M. Tiripicchio Camellini, J. Organometal. Chem., 316, C35 (1986).

[55] E. O. Fischer, H. A. Goodwin, C. G. Kreiter, H. D. Simmons, Jr., K. Sonogashira, and S. B. Wild, J. Organometal. Chem., 14, 359 (1968).

[56] C. C. Lee, B. R. Steele, and R. G. Sutherland, J. Organometal. Chem., 186, 265 (1980).

[57] C. G. Kuehn and H. Taube, J. Am. Chem. Soc., 98, 689 (1976).

[58] N. Kuhn and H. Schumann, J. Organometal. Chem., 276, 55 (1984).

[59] M. Draganjac, C. J. Ruffing, and T. B. Rauchfuss, Organometallics, 4, 1909 (1985).

[60] N. N. Sauer and R. J. Angelici, Inorg. Chem., 26, 2160 (1987).

[61] S. C. Huckett, N. N. Sauer, and R. J. Angelici, Organometallics, 6, 591 (1987).

[62] J. W. Hachgenei and R. J. Angelici, Angew. Chem., 99, 947 (1987).

[63] G. H. Spies and R. J. Angelici, Organometallics, 6, 1897 (1987).

[64] R. T. Weberg, R. C. Haltiwanger, J. C. V. Laurie, and M. Rakowski DuBois, J. Am. Chem. Soc., 108, 6242 (1986).

[65] G. H. Spies and R. J. Angelici, J. Am. Chem. Soc., 107, 5569 (1985).

[66] N. N. Sauer and R. J. Angelici, Organometallics, 6, 1146 (1987).

[67] M. Rakowski DuBois, M. C. VanDerveer, D. L. DuBois, R. C. Haltiwanger, and W. K. Miller, J. Am. Chem. Soc., 102, 7456 (1980). 
[68] M. Rakowski DuBois, D. L. DuBois, M. C. VanDerveer, and R. C. Haltiwanger, Inorg. Chem., 20, 3064 (1981).

[69] M. Rakowski DuBois, J. Am. Chem. Soc., 105, 3710 (1983).

[70] M. McKenna, L. L. Wright, D. J. Miller, L. Tanner, R. C. Haltiwanger, and M. Rakowski DuBois, J. Am. Chem. Soc., 105, 5329 (1983).

[71] C. J. Casewit, D. E. Coons, L. L. Wright, W. K. Miller, and M. Rakowski DuBois, Organometallics, 5, 951 (1986).

[72] C. J. Casewit, R. C. Haltiwanger, J. Noordik, and M. Rakowski DuBois, Organometallics, 4, 119 (1985).

[73] C. J. Casewit and M. Rakowski DuBois, J. Am. Chem. Soc., 108, 5482 (1986).

[74] G. A. Somorjai, in Proceedings 8th Int. Congress on Catalysis, Berlin, Verlag Chemie, Weinheim, 1984, p. I-113.

[75] M. Salmeron and G. A. Somorjai, Surf. Sci., 126, 410 (1983).

[76] A. J. Gellman, M. H. Farias, M. Salmeron, and G. A. Somorjai, Surf. Sci., 136, 217 (1984).

[77] D. G. Kelly, M. Salmeron, and G. A. Somorjai, Surf. Sci., 175, 465 (1986).

[78] J. Stöhr, J. L. Gland, E. B. Kollin, R. J. Koestner, A. L. Johnson, E. L. Muetterties, and F. Sette, Phys. Rev. Lett., 53, 2161 (1984).

[79] F. Zaera, E. B. Kollin, and J. L. Gland, Surf. Sci., 184, 75 (1987).

[80] J. F. Lang and R. I. Masel, Surf. Sci., 183, 44 (1987).

[81] J. Stöhr, E. B. Kollin, D. A. Fischer, J. B. Hastings, F. Zaera, and F. Sette, Phys. Rev. Lett., 55, 1468 (1985).

[82] F. Zaera, E. B. Kollin, and J. L. Gland, Langmuir, 3, 555 (1987).

[83] B. A. Sexton, Surf. Sci., 163, 99 (1985).

[84] J. T. Roberts and C. M. Friend, J. Am. Chem. Soc., 108, 7204 (1986).

[85] J. B. Benziger and R. E. Preston, J. Phys. Chem., 89, 5002 (1985).

[86] R. E. Preston and J. B. Benziger, J. Phys. Chem., 89, 5010 (1985).

[87] G. R. Schoofs, R. E. Preston, and J. B. Benziger, Langmuir, 1, 313 (1985).

[88] U. Gelius, B. Roos, and P. Siegbahn, Theoret. Chim. Acta, 27, 171 (1972).

[89] T. L. Gilchrist, in Heterocyclic Chemistry, Pitman Publ. Inc., London, 1985 , pp. 154 and 156.

[90] A. J. Gellman, D. Neiman, and G. A. Somorjai, J. Catal., 107, 92 (1987).

[91] A. J. Gellman, M. E. Bussell, and G. A. Somorjai, J. Catal., 107, 103 (1987).

[92] M. E. Bussell and G. A. Somorjai, J. Catal., 106, 93 (1987).

[93] J. P. R. Vissers, J. Bachelier, H. J. M. Ten Doeschate, J. C. Duchet, V. H. J. de Beer, and R. Prins, in Proceedings 8th Int. Congress on Catalysis, Berlin, Verlag Chemie, Weinheim, 1984, p. II-387.

[94] J. P. R. Vissers, B. Scheffer, V. H. J. de Beer, J. A. Moulijn, and R. Prins, J. Catal., 105, 277 (1987). 
[95] R. L. Seiver and R. R. Chianelli, U.S. Patent 4431747 (1984).

[96] R. Ramachandran and F. E. Massoth, Can. J. Chem. Eng., 60, 17 (1982).

[97] J. S. Lee and M. Boudart, Appl. Catal., 19, 207 (1985).

[98] Y. J. Kuo, R. A. Cocco, and B. J. Tatarchuck, J. Catal., 112, 229,250 (1988).

[99] R. J. H. Voorhoeve, J. Catal., 23, 236 (1971).

[100] A. J. A. Konings, A. M. van Dooren, D. C. Koningsberger, V. H. J. de Beer, A. L. Farragher, and G. C. A. Schuit, J. Catal., 54, 1 (1978).

[101] A. J. A. Konings, W. L. J. Brentjens, D. C. Koningsberger, and V. H. J. de Beer, J. Catal., 67, 145 (1981).

[102] A. J. A. Konings, A. Valster, V. H. J. de Beer, and R. Prins, J. Catal., 76466 (1982).

[103] B. G. Silbernagel, T. A. Pecoraro, and R. R. Chianelli, J. Catal., 78, 380 (1982).

[104] E. G. Derouane, E. Pedersen, B. S. Clausen, Z. Gabelica, R. Candia, and H. Topsøe, J. Catal., 99, 253 (1986).

[105] Z. Shuxian, W. K. Hall, G. Ertl, and H. Knözinger, J. Catal., 100, 167 (1986).

[106] G. Hagenbach, Ph. Courty, and B. Delmon, J. Catal., 31, 264 (1973).

[107] R. Candia, B. S. Clausen, and H. Topsøe, Bull. Soc. Chim. Belg., 90, 1225 (1981).

[108] M. L. Vrinat and L. de Mourgues, Appl. Catal., 5, 43 (1983).

[109] J. V. Sanders and K. C. Pratt, J. Catal., 67, 331 (1981).

[110] F. J. Gil-Llambías, M. Escudey Castro, and L. Bouyssieres McLeod, $J$. Catal., 88, 222 (1984).

[111] K. C. Pratt, J. V. Sanders, and N. Tamp, J. Catal., 66, 82 (1980).

[112] B. Delmon, Bull. Soc. Chim. Belg., 88, 979 (1979).

[113] S. Eijsbouts, V. H. J. de Beer, and R. Prins, J. Catal., 109, 217 (1988)

[114] R. R. Chianelli, T. A. Pecoraro, T. R. Halbert, W.-H. Pan, and E. I. Stiefel, J. Catal., 86, 226 (1984).

[115] S. Harris and R. R. Chianelli, J. Catal., 98, 17 (1986).

[116] S. Harris and R. R. Chianelli, J. Catal., 86, 400 (1984).

[117] P. R. Wentrcek and H. Wise, J. Catal., 51, 80 (1978).

[118] S. J. Tauster, T. A. Pecoraro, and R. R. Chianelli, J. Catal., 63, 515 (1980)

[119] J. Bachelier, J. C. Duchet, and D. Cornet, J. Phys. Chem., 84, 1925 (1980).

[120] W. Zmierczak, G. MuraliDhar, and F. E. Massoth, J. Catal., 77, 432 (1982).

[121]. R. R. Chianelli and M. Daage, private communication.

[122] J. Bachelier, J. C. Duchet, and D. Cornet, J. Catal., 87, 283 (1984).

[123] J. Bachelier, J. C. Duchet, and D. Cornet, Bull. Soc. Chim. Belg., 90, 1301 (1981).

[124] J. Bachelier, M. J. Tilliette, M. Cornac, J. C. Duchet, J. C. Lavalley, and D. Cornet, Bull. Soc. Chim. Belg., 93, 743 (1984). 
[125] J. Miciukiewicz, W. Zmierczak, and F. E. Massoth, Bull. Soc. Chim. Belg., 96, 915 (1987).

[126] V. H. J. de Beer, J. C. Duchet, and R. Prins, J. Catal., 72, 369 (1981).

[127] R. Burch and A. Collins, J. Catal., 97, 385 (1986).

[128] J. P. R. Vissers, V. H. J. de Beer, and R. Prins, J. C. S. Faraday Trans. $I, \mathbf{8 3}, 2145$ (1987). 